\title{
BIOLOGIA E CONTROLE DE Clasmopalpus lignosellus (Zeller, 1848) (Lepidoptera - Pyralidae), EM TRIGO
}

\section{KAZUIYUKI NAKAYAMA}

Orientador: Prof. Dr. Octávio Nakano

Dissertaçāo apresentada à Escola Superlor de Agricultura "Lulz de Quelroz". da Universidade de Sảo Paulo, para obtençāo do titulo de Mestre em Entomologla

PIRACICABA Estado de São Paulo - Brasil

Dezembro - 1980 
.$e$.

Para Iuiza Hitomi

minha esposa

DEDICO 


\section{Agradecimentos}

.ii.

Ao Prof. Dr. Octávio Nakano, pela valiosa orientação, apoio e estímulo cong tante, antes e durante o decorrer do curso.

Aos Professores: Dr. Domingos Gallo, Chefe do Departamento de Entomologia, Dr. Sinval Silveira Neto, Dr. José Roberto Postali Parra, Dr. Gilberto Casadei de Batista, Dr. Roberto Antonio Zucchi, Dr. Sergio Batista Alves e Dr. José Djair Vendramim pelas sugestões, amizade e consideração dis pensada.

Ao Prof. Dr. Evôneo Berti Fizho, pela amizade, consideração e pela versão do resumo em inglès.

A Tiemi Matsuo, pela amizade, consideração e análises estatísticas.

Ao Luiz Katsumi Yabase, pela amizade, consideração e confecção do gräfico.

Ao Engenheiro Agrónomo Shizuo Dodo, pela amizade, estímulo e consideração.

Aos Estagiários do Departamento de Entomologia da ESALQ, pertencentes ao Se tor de Entomologia Aplicada, pela colaboração.

Aos Funcionários do Departamento de Entomologia pela atenção, amizade e ser viços prestados.

A todos os funcionários da Biblioteca da ESALQ, de modo especial ao Sr. Luiz Carlos Verissimo, pela solicitude no atendimento.

Ao Conselho Nacional de Desenvolvimento Cientifico e Tecnolögico - CNPq, pe la concessão da bolsa de estudo a nível de Mestrado. 


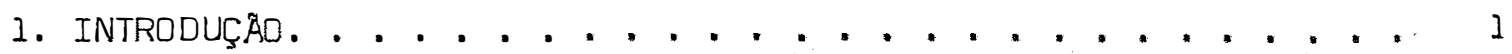

2. REVISÃD DE LITERATURA ..................... 2

2.1. Bioecologia ................ 2 2

2.2. Efeito de Umidade do Solo na Sobrevivéncia da lagarta E. lignosellus. . . . . . . . . . . . . 6

2.3. Avaliação de danos. . . . . . . . . . . . . >

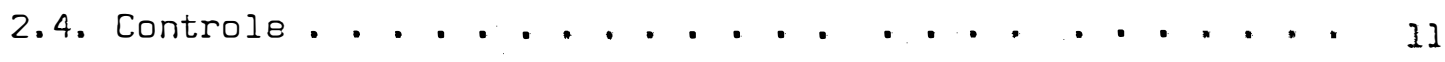

3. MATERIAIS E MÉTODOS. .........................

3.1. Criação Massal. . . . . . . . . . . . . . 17

3.1.1. Obtenção dos insetos no campo ......... 17

3.1.2. Manuseio e sexagem das pupas . . . . . . . . . 17

3.1.3. Manuseio e alimentação.dos adultos........ 18

3.1.4. Obtenção e manuseio de ovos............ . 19

3.1.5. Preparação e manuseio do substrato e das lagartas. 19

3.1.5.1. Preparação do vaso de alimentação ... 19

3.1.5.2. Manuseio e alimentação das lagartas. . . 21

3.2. Dados biológicos................ 21

3.2.1. ovo................. 21

3.2.2. Lagartas. . . . . . . . . . . . 21

3.2.2.1. Experimento para determinação do crescimen to de lagartas de E. lignoscllus. . . . . 22

3.2.3. Pupa. . . . . . . . . . . . . . 23

3.2 .4 . Adulto. ................... 23

3.3. Avaliação de dano. . . . . . . . . . . . . 23

3.4. Preparaçào e materiais utilizados nos ensaios preliminares de Controle Químico e Controle com irrigaçäo..... 25 
3.5. Efeito da frequéncia de irrigação por Aspersão sobre lagar tas E. lignosellus. . . . . . . . . . . . 25

3.6. Dados referentes à cultura dos Ensaios de Controle. . . . . 27

3.7. Tipos de aplicação e distribuição dos Inseticidas utilizados nos ensaios de controle................ . . 28

3.7.1. Pulverização do Sulco. . . . . . . . . . . . " 28

3.7.2. Tratamento de sementes. . . . . . . . . . . 28

3.7.3. Granulados no Sulco. . . . . . . . . . . . 28

3.8. Controle. . . . . . . . . . . . . . . . . 29

3.8.1. Experimento fase preliminar e Seletiva I. . . . . . 29

3.8.2. Experimento fase preliminar e Seletiva II. . . . . . 30

3.8.3. Experimento Confirmativo. . . . . . . . . . . 31

3.9. Da Análise Estatística. . . . . . . . . . . . . 33

4. Resultados e discussão. . . . . . . . . . . . . . . . . . 34

4.1. Dados Biológicos. . . . . . . . . . . . . . 34

4.1.1. Ovo . . . . . . . . . . . . . . . 34

4.1.2. Lagarta. . . . . . . . . . . . . . . 35

4.1.2.1. Descrição da lagarta. . . . . . . 36

4.1.2.2. Desenvolvimento larval. ....... 36

4.1.3. Pré-pupa. . . . . . . . . . . . . . . 38

4.1.4. Рupa....................... 38

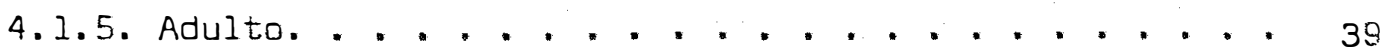

4.1.5.1. Pré-ovoposição. . . . . . . . . 39

4.1.5.2. Postura. . . . . . . . . . 4]

4.1.5.3. Longevidade. . . . . . . . . . 4]

4.1.6. Ciclo Biológico. . . . . . . . . . . . . 4 43

4.2. Efeito da frequéncia de irrigação sobre lagartas de E. ligno selkus. . . . . . . . . . . . . . . . 44 44

4.3. Avaliaçào de dano. . . . . . . . . . . . . . . . . 47

4.3.1. Sintoma do dano. ............... 47 47 
4.3.2. Número provável de plantas de milho, sorgo sacarino, trí go, агroz, soja e feijão, danificadas por lagarta de $E$. lignosellus.................... 47

4.4. Controle. . . . . . . . . . . . . . . . . 49

4.4.1. Fase Seletiva I. . . . . . . . . . . . 49

4.4.2. Fase Seletiva II. . . . . . . . . . . . . 52

4.4.3. Experimento Confirmativo. . . . . . . . . . . 55

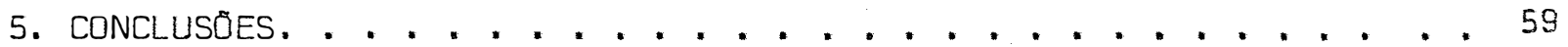

6. LITERATURA CITADA. . . . . . . . . . . . . . . . . . 62 
.vi.

\section{BIOLOGIA E CONTROLE DE Ezasmoparpüs ž̈gnosezrus \\ (ZELLER, 1848) (Lepidoptera - Pyralidae), EM TRIGO}

AUTOR: Kazuiyuki Nakaycona

ORIENTADOR: Octãvio Nakano

RESUMO

Elasmopalpus Lignosellus (ZeZzer, 1848). (Lepidoptera, Pyra-

lidae) é uma das pragas mais nociva a muitas culturas. Não obstante, são poucos os trabalhos relacionados com os aspectos básicos deste inseto. Eg te trabalho propõe-se a estudar a biologia e os hábitos de E. lignosellus, fornecendo subsídios à adoção de uma melhor estratégia de controle. As lagartas foram alimentadas com plàntulas de trigo germinadas em vasos plásticos e os adultos foram alimentados com solução de sacarose a $20 \%$ Os insetos foram mantidos a $27 \pm 5^{\circ} \mathrm{C}$ e $70 \pm 10 \%$ de umidade relativa. Os estágius de desenvolvimento apresentaram as seguintes durações médias: 3 dias para incubação das ovos; 10,74 dias para o período larval e prë-pu pal; 5,2 dias para o período pupal; 2,0 dias para o período de pré-ovopos ção; 8 dias para o período de ovoposição. O número médio de fémeats/ovo foi de 54,36; A longevidade do adulto foi de 8,5 dias para os machos e 
vir.

6,35 dias para as fémeas; o ciclo de vida total foi de 26,9 dias em mé dia. Experimentos foram instalados em casa de vegetação a fim de avaliar os danos do inseto e controle. No experimento de dano,duas lagartas recem-eclodidas de $E$. lignosellus foram colocadas em plantas com 5 dias de germinadas, de milho, sorgo sacarino, trigo, arroz, soja e feijão. Os da nos médios por lagarta foram: 2,57; 9,$78 ; 7,06 ; 8,73 ; 2,73$ e 2,40 plantas de milho, sorgo sacarino, trigo, arroz, soja e feifão, respectivamente. Nos experimentos de controle, caixas contendo um metro linear de plantas de trigo foram utilizadas nos ensaios de controle com inseticidas ( 3 expe rimentos) e irrigação (I experimento), avaliando-se o efeito dos inseticị das e da irrigação através do número de plantas danificadas. Irrigações por asperção com intervalos de 3 e 6 dias reduziram o número de plantas da nificadas para $0 \%$ e $3,0 \%$, e a viabilidade larval para 0,0 e $2,5 \%$, respecti vamente, quando comparada com a testemunha. Os inseticidas foram aplicados de diferentes formas: pulverizados no sulco de semeadura, tratamento de semente e inseticidas granulados no sulco. A infestação de E. lignosellus foi feita com 30 ovos e 10 lagartas por caixa. A \% de germinação e o núme ro de plantas danificadas foram avaliadas nos trés experimentos com insetj cidas. Os seguintes inseticidas, em gramas de ingrediente ativo por hectare, não reduziram a germinação das sementes de trigo, quando pulverizados nos sulcos: clorpirifos Etil EC $(835 \mathrm{~g}, 1200 \mathrm{~g}, 1800 \mathrm{~g}$ e $2400 \mathrm{~g})$; fonofos EC (1500 g); carbofuran F (875 g e $1400 \mathrm{~g})$; sulfona de aldicarb PM(1500g): tiodicarb PM (1500 g); acefate PS (1600 g); etoprop EC (1000 g e $1260 \mathrm{~g})$, e clorpirifos etil G (1800 g e $2100 \mathrm{~g})$. Os inseticidas, propoxur PM(2000g). clorpirifos etil EC (1800 g) acefate PS $(1500 \mathrm{~g})$, em gramas de ingrediente 
.viii. ativo por $120 \mathrm{~kg}$ de sementes de trigo, reduziram a germinaçäo. Em trata mento de semente, os inseticidas que não afetaram a germinação foram: metä midofos EC, carbofuran F e sulfona de aldicarb PM, nas dosagens de $1500 \mathrm{~g}$, $1000 \mathrm{~g} \mathrm{e} 1500 \mathrm{~g}$, respectivamente. Um bom controle foi obtido com os seguintes inseticidas, em gramas de ingrediente ativo por hectare; fonofos EC (1000 g), clorpirifos etil (1800 g), clorpirifos etil G (2100 g) e carbofuran F (1000 g). 


\section{BIOLOGY AND CONTROL OF Ezasmoparpus zignosezius (ZELLER, 1848) (LEPIDOPTERA - PYRALIDAE), ON WHEAT CROP}

\section{SUMMARY}

Elasmopalpus lignosellus (ZeZZer, 1848) (Lepidoptera, Pyralidae) is one of the most serious pests on many crops. Notwithstanding, there are few works dealing with the basic aspects of this insect. This research aimed to study the biology and the habits of E. lignosellus so as to provide data for a better strategy of control. The larvae were fed with wheat seedlings grown in plastic tubes and the adults were fed with a $20 \%$ sucrose solution. The insects were kept in laboratory conditions $\left(27 \pm 5^{\circ} \mathrm{C}\right.$ and $70 \pm 10 \%$ R.H. $)$. The developmental stages presented the following mean lengths: 3.0 days for egg incubation: 10.74 days for the larva and pre-pupa period; 5.2 days for the pupa period; 2.0 days for the pre-ovoposition period; 8.0 days for the ovoposition period. The number of eggs per female averaged 54.36. The adult longevity averaged 8.60 days for the males and 6.35 days for the females; the total life cycle averaged 26.9 days. Two experiments were set in greenhouse in order to evaluate the insect damage and control. In the damage experiment two newly hatchad 
larvae of $E$. lignosellus were placed in each 5-day old plants of maize, sacarine sorghum, wheat, rice, soybean and bean. The mean damage p.er larva was $2.57 ; 9.78,7.06,8.73,2.73$ and 2.40 plants of maize, sacarine sorghum, wheat, rice, soybean, and bean, respectively. In the control experiment boxes containing one linear meter of wheat plants were used to test the control with insecticides ( 3 experiments) and irrigation (1 experiment). The number of damaged plants was used to evaluate the effect of insecticides and irrigation. The sprinkling irrigation at intervals of 3 and 6 days reduced the damage plants to $0 \%$ and $3.0 \%$ and the larval viability to $0.0 \%$ and $2.5 \%$, respectively, when compared to the checks. The chemicals were applied in three different ways: sprayed in the sowing furrows, treated seeds, and granulated insecticide in the furrows. The infestation was made with eggs (30 eggs per plot) and larvae (10 larvae per plot) of E. lignosellus. The percentage of germination and the number of damaged plants were evaluated in the three experiments with insecticides. The following insecticides, in grams of active ingredient per hectare, did not reduce wheat seed germination when sprayed in the furrows: chlorpiriphos ethyl EC $(835 \mathrm{~g}, 1,200 \mathrm{~g}, 1,800 \mathrm{~g}, 2,400 \mathrm{~g})$ s fonophos EC $(1,500 \mathrm{~g})$; carbofuran $F(875 \mathrm{~g}$ and $1,400 \mathrm{~g})$, aldicarb sulfona WP $(1,500 \mathrm{~g})$; tiodicarb WP $(1,500 \mathrm{~g})$; acephate SP $(1,600 \mathrm{~g})$; ethoprop EC $(1,000$ and $1,260 \mathrm{~g})$ and chlorpiriphos ethyl $\mathrm{G}(2,100 \mathrm{~g})$. The insecticides propoxur WP $(2,000 \mathrm{~g})$, chlorpiriphos ethyl EC $(1,800 \mathrm{~g})$, acephate SP $(1,500 \mathrm{~g})$, in grams of the active ingredient per 120 kilograms of seeds, reduced seed germination. Concerning the insecticide treated seeds the chemicals that did not affect germination were: metamidophos EC, carbofuran 1 , 
.xi. and aldicarb sulfona WP, in the dosages of $1,500 \mathrm{~g}, 1,000$ and $1,500 \mathrm{~g}$, , respectively. A good control was obtained with the following insecticides, in grams of the active ingredient per hectare: fonophos EC $(1,000 \mathrm{~g})$, chlorpiriphos ethyl EC $(1,800 \mathrm{~g})$, chlorpiriphos ethyl $\mathrm{G}(2,100 \mathrm{~g})$ and carbofuran $F(1,000 \mathrm{~g})$. 


\section{INTRODUÇĀO}

A lagarta Elasmo, Elasmopalpus lignosellus (ZeZZer, 1848) [Lepidoptera, Pyralidae), constitui uma das principais pragas de solo, de diversas plantas causando elevados danos em gramíneas como trigo, arroz, milho, cana e leguminosas como soja, feijão, amendoim, além de atacar oü tros grupos de plantas cultivadas como; algodão, pinheiro, eucalipto e ca fé.

Observa-se que esta praga tem sido favorecida pelas condi ções de altas temperaturase baixa precipitação, atacando a região de cole to das plantas, produzindo um sintoma típico conhecido por "coração morto", nas gramíneas, acarretando a morte das mesmas.

Recentemente, com a abertura de novas äreas agrícolas repre sentadas principalmente pela exploração de regiões de cerrado nos estados de Goiás, Mato Grosso, Mato Grosso do Sul e Minas Gerais, o problema da elasmo tem-se agravado, principalmente porque nessas äreas é comum a ocor rência de "veranicos", isto é, pequenos períodos de seca durante a ëpoca chuvosa de verão, que aliado ao plantio em grande escala tem propiciado 
ataques bastante significativos. Dessa forma, as culturas'que têm. 'sido mais prejudicadas são: arroz, no período de novembro a dezembro e o trigo. no período de abril a maio, constituindo-se num dos maiores problemas fí tossanitários dessas culturas, concorrendo para reduzir a produtividade, especialmente no caso do trigo que é o segundo produto de importação do país, cujo valor em 1980 foi de aproximadamente 800 milhões de dólares para sua aquisição.

$\therefore \quad$ Diversos trabalhos já foram desenvolvidos com esse inseto, más a dificuldade de sua criação tem dificultado a obtenção de informações mais concretas sobre essa praga, mormente em relação ao seu controle racio nal.

Assim sendo, desenvolveu-se no presente trabalho uma técni ca de criação massal de elasmo, em dieta natural, que permitiu os estudos de avaliação de dano e controle dessa praga, na cultura do trigo. 


\section{REVISAO DE LITERATURA}

A lagarta Elasmo, Elasmopalpus lignosellus (Zezler, 1848) [Lepidoptera, Pyralidae), é considerada um dos insetos mais prejudiciais às plantas cultivadas. Muito embora, seja importante praga de diversas cul turas de expressão económica, tais como: cana-de-açúcar, trigo, sorgo, amendoim, soja, milho, caupi e arroz, são poucas as pesquisas com esse inssto, no Brasil, notadamente em relação à sua biologia.

\subsection{Bioecologia}

As primeiras citaçōes relativas a sua ocorróncia em plan tas cultivadas foram feitas por Lungibilz e Alnslie (1917), citados por SAUER (1939), em ervilha, amendoim, trigo e cana-de-açúcar.

PIANK (1928) fez a descrìção sumária das características morfológicas do inseto adulto e da larva, além de relatar informações so bre o ciclo biológico de E. Rignosellus, tais como: duração do período pu pal (6-e dias) e duração do período larval (13 dias). Informaçôes mais 
completas foram fornecidas por SAUER (1939) que obteve 129 ovos por fímea e viabilidade larval de 3,5\% para lagartas de.Elasmo alimentadas com fo Ihas de arroz.

Lungibizl e Ainslie (1917) citados por HAYWARD (1943), de terminaram 4 a 6 ecdises, e que o comprimento das lagartas recém-eclodidas era de $1,7 \mathrm{~mm}$.

Durante a década de 50, poucas foram as informações relacio nadas com a biologia de E. lignosellus. Foi na década de 60 que os parä metros pertinentes ao seu ciclo biológico foram dimensionados.

DUPREE (1965) otteve dados da duração do ciclo biológico de E. lignosellus, determinando o número de gerações possiveis (3), durante o verão da Geórgia, EUA, bem como a aplicabilidade da regra de Dyar no cres cimento larval de E. lignosellus. A duração do ciclo biológico por ele determinado foi de 77,80 dias.

LEUCK (1966) verificou que o ciclo biológico desta praga na Geórgia, EUA, foi de $43 \pm 3,5$ dias, de óvo ao adulto. As lagartas eclodi ram em 3 dias, os ovos foram postos nas faces inferiores das folhas e os adultos possuiam uma longevidade de 10,3 0 0,7 dias. A razão de crescimen to foi de 1,44 possuindo o ciclo larval 6 ínstares, sendo o último o de maior duraçào $\{8,6 \pm 0,5\}$ dias; observou também que a duração do período pupal esté estreitamente relacionada com a temperatura.

A técnica de criação massal de E. Rignoscllus foi desenvol 
.5.

vida por STONE (1968), que obteve $80 \%$ de viabilidade larval com as lagar tas de E. lignosellus, desenvolvendo-se em dieta artificial, composta de caseína, saìs de Wesson, sacarose, formaldeido, ácido sórbico, nipagin, germe de trigo, agar, mistura vitamínica, sulfato de streptomicina, ácido ascórbico, hidráxido de potássio e água. A duração de seu ciclo evolutivo foi de 26 dias e essa população foi multiplicada nesse tipo de dieta por 19 gerações.

o número de espermatóforos transferidos do macho para a fú mea foi estudado por STONE (1968), tendo determinado que, as proporções de I macho 1:2:3:4 fémeas, não alterava o número de espermatóforos transferi dos, e que o macho transferia um espermatóforo por noite à temperatura de $29^{\mathrm{O}} \mathrm{L}$ e $30-35 \%$ U.R.

CHALFANT (1935) descreveu uma técnica para a criação mas sal de E. lignosellus, onde ele obteve uma longevidade para o adulto macho de 8 dias e 5 dias para a fémea, e período de pré-ovoposição de 3 dias; o pico de ovoposição ocorreu no $5^{8}$ dia e o número de ovos por fémea foi de 47, sendo que o substrato preferido para o ovoposição foi o papel poroso de coloração azul.

A sobrevivéncia de lagarta elasmo tem sido referida como sendo maior em solo arenoso, CHAGAS (1978). CHALFANT (1975) obteve viab1 lidade larval extremamente alta com adição de vermiculita sobre dieta art 1 ficial, e viabilidade larval nula com adição de areia fina sobre as mes mas. 
.6 .

\subsection{Efejto de Umidade do Solo na Sobrevivēncia da Lagarta E. Lignosel lus}

A umidade do solo vem sendo relacionada com a maior ou me nor ocorréncia da lagarta Elasmo nas culturas há muito tempo. PLANCK (1928) afirmava que solos extremamente secos aumentavam a incidència des sa praga na cultura de cana-de-açūcar.

SAUER (1939) estabeleceu que semeaduras antecipadas de ar roz, no norte do Estado de São Paulo, sofriam maiores infestações quando logo após a semeadura ocorria um período de seca.

FEHN e MOTA (1959) fizeram semeadura de milho com interva lo de 10 dias, durante 5 anos, de 1952 a 1957, de setembro a dezembro, no Estado do Rio Grande do Sul, e correlacionaram as umidades do solo 10 dias antes e 10 dias após a semeadura, concluindo serinegável a relação existen te entre a umidade do solo e o ataque de $E$. lignosellus nessa cultura.

BERTELS (1970), através de dados obtidos na década de 50. concluiu em seus estudos de influéncia da umidade sobre a dinámica de pe pulações de lepidopteros, pragas de milho, que para E. lignoscllus, cujo ciclo biológico em grande parte está ligado ao solo, a umidade tem papel decisivo. Os períodos de chuvas, que antecedem o plantio de milho na zona litoránea do Rio Grande do Sul, eliminaram quase por completo o perigo de futuras invasões de gerações primaveris desta espécie. Ao contrário, as estiagens favorecem o aumento populacional da praga de tal maneira, que os estragos causados pelas lagartas atingem 90 até 100\% de perda das plán 
tulas de milho.

O teor de umidade do solo, associado a tipos de cultivos de solo, e correlacionados com as infestaçães de lagarta Elasmo, na cultura do milho, foi analisado por ALL e GALLAHER (1977). Verificaram que a umidade total do solo sobre cultivo mínimo é mais alta que a umidade do solo sobre o cultivo tradicional, independente do tipo de solo. Para os diversos tipos de solo examinados, a tensão da água foi de $0,05 \pm 0,3$ ba no sístema de cultivo mínimo irrigado. A água do solo, no sistema convencional irri gado, foi significativamente mais baixa e sofreu intensa variação no mesmo período. A umidade do solo não irrigado sobre o sistema convencional fol de

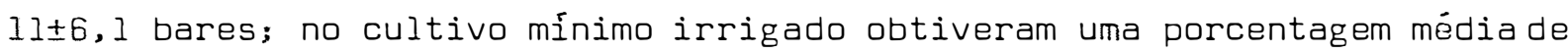
redução no "stand" de $1,30 \%$ e $0,7 \%$ para o não irrigado; para os solos sob o cultivo convencional irrigado, obtiveram a porcentagem média na redução do "stand" de $7,7 \%$ e $23,5 \%$ para o solo sob o mesmo sistema de cultivo e ir rigado.

ALL et alii (2979) concluiram, através dos seus experimen tos que, em condições de seca, a irrigação na semeadura e sua suplementa ção, somente quando necessária para a planta, proporciona pequena diminui ção nas infestações de E. lignosellus na cultura do milho, provavelmente devido ao fato de que, sem a suplementação mais amiūde, a camada (1-3 cm) superficial do solo seca rapidamente logo após a irrigaçäo, e essas condições são favoráveis ao desenvolvimento da lagarta elasmo.

\subsection{Avaliação de Danos}

As experimentações concernentes aos danos da laģarta L lasmo 
às diferentes culturas são escassas, especialmente na cultura do trigo.

A sintorotologia do ataque de lagarta elasmo em cana-de-açú car foi descrita por PLANK (1928), que caracterizou o "coração morto" de uma planta de cana atacada pelo murchamento inicial e posterior secamento da folha central. Para diferenciar do sintoma de Diatraca saccharalis, re comenda a localização dos tubos de seda e areia junto ao colo da planta de cana-de-açúcar, elemento marcante da presença da elasmo.

SAUER (1939) descreveu o sintoma de ataque da lagarta elas mo à cultura do arroz, e determinou que uma lagarta poderia danificar 4 plantas, em condições de campo.

LEUCK (1963), utilizando infestação artificial com ovos de 3 dias de idade, na cultura de amendoim de 70 dias de idade, obteve as se guintes equações:

$$
y_{1}=8,57+0,03 x_{1} \text {, }
$$

onde: $x_{1}=n^{+}$de ovos/5 plantas, médìas de 3 repetições;

$y_{1}=n^{8}$ de vagens danificadas.

$$
y_{2}=12,54+0,12 x_{2},
$$

onde: $x_{2}=n^{8}$ de ovos/5 plantas, média de 3 repetições;

$y_{2}=n^{8}$ de brotos laterais danificados.

NAKANO E SILVEIRA NETO (1975) estabeleceram que, para as culturas como a soja, feijão e gramíneas como trigo, arroz, milho e sorgo, o dano nos primeiros 30 dias de idade das culturas podem sor aqui- 
latados através do número de plantas mortas. A fórmula para determínaçào do nível de controle (NC) é a seguinte:

$$
N C=\frac{N^{8} \text { de plantas mortas/ha } \times \text { Ct }}{V} .
$$

onde, infestação $=n^{8}$ de plantas mortas/ha;

$C t=$ custo do tratamento $\left(C_{r} \$ / h a\right)$;

$V=$ estimativa da produção média da cultura (Cr\$/ha).

SMITH JONIOR e HOLLOWAY (1979) Utilizaram uma cultivar co mercial de amendoim, instalada em solo arenoso não irrigado, infestandora com os seguintes níveis: $2.500 ; 12.500 ; 25.000 ; 37.000,50.000$ e 60.000 lagartas elasmo/ha, durante 20 a 50 dias de idade da cultura. Estabelece ram que, no período de 20 a 50 dias após a germinação, infestaçōes de $0<$ $x<14,448,0$ lagartas elasmo/ha são toleradas pelo amendoim, sem decrésci mo na produção.

$$
\text { BERBERET et alii (1939) estabeleceram, para a cultura do }
$$

amendoim, que nos 65 primeiros dias de idade da cultura as perdas na pro dução podem ser determinadas pela equação

$$
y=-9,87 x
$$

onde, $y$ = redução na produção de vagens em kg/ha;

$x=\%$ de infestação em 100 plantas examinadas, para uma cultura ins talada em solo arenoso, espaçada de $0,60 \mathrm{~cm}$ entre linha e sem irrigaçäo. Os níveis de infestação foram obtidos através de aplicação de diferentes doses de clorpirifos $(2,2 ; 1,1 ; 0,6$ e $0,3 \mathrm{~kg} \mathrm{i.a/ha)} \mathrm{e} \mathrm{carbofuran} \mathrm{(2,2,}$ 
1,1 e 0,1 g i.a/hal.

ALL et alii (1939), em suas avaliaçães de 1nfestação, cons1 deraram plantas de milho infestadas, àquelas com sintoma de "coração mor to" ou planta morta. Comparando o dano na produção da parcela testemunha e das parcelas com inseticidas, e correlacionando as infestaçães de diver sos ensaios, obtiveram a equação (1)

(I) y (lem $\%$, de grãos $)=0,98 \times(\%$ de infestação $)+0,53$;

$r=0,94$, para produção de grãos de milho;

e equação (2), para produção de ensilagem;

(2) y $\left(\begin{array}{l}\% \text { de produção } \\ \text { ensilagem perdida }\end{array}\right)=1,64 \times(\%$ de plantas infestadas $)+3,34$; $r=0,78$.

A utilização de inseticidas e outras práticas culturais lcon tróle preventivo de erva daninha, irrigação, etc.), na produção de milho, determinado por ALL et alii (1979), mostrou que $1 \%$ na redução da infesta ção resultou em aumento na produção de grãos de $2,384 \%$.

MARTINS et aZii (1980) amostraram a lagarta elasmo em cul t ura de arroz de sequeiro, coletando o solo contido por uma caixa de $15 x$ $20 \times 20 \mathrm{~cm}$. Do solo coletado e homogeneizado sobre plástico, foi tomada a alíquota de 1,0 litro de solo, e contado o número de lagarta elasmo. Es sa amostragem permitiu concluir que l lagarta/litro de solo provocou 1: de perfilhos mortos. 


\subsection{Controle.}

REINOLDS et alii (1959) testaram vários produtos e diversas formas de aplicação e concluiram que os inseticidas mais efetivos na pro teção das plântulas de soja foram: endrin, aldrin, heptaclor e dieldrin, nas dosagens de $2,2 \mathrm{~kg}$ de i.a/ha e que houve pouca diferença entre as for mulações líquidas e granuladas, aplicadas sobre a superfície do solo, de vendo os tratamentos ter caráter preventivo.

O efeito associado do uso de inseticida após a irrigação foi estudado por esses autores, no mesmo trabalho, na cultura de sorgo (Sorghum vulgare), sendo irrigado por inundação. Entretanto, os produtos tiveram a mesma eficiència, e o trato cultural mais eficiente na redução da infestação de E. lignosellus foi a destruição das plantas hospedeiras daninhas antes do plantio.

D volume da calda necessário ao sucesso do controle foi es tudado por CUNNINGHAN et alii (1959), os quais verificaram que a utilização de 185, 370 e 740 litros de calda/ha não aumentava a eficiència de endrin quando aplicado em pulverização. A variação do intervalo entre aplicações com DDT $[21,14$ e 7 dias) não causou diferença significativa entre os tra tamentos.

Diferentes formulações foram estudadas por HARDING (1960)

durante anos, onde foram testados os seguintes produtos, em gramas do i.a/ha, em cultura de amendoim; DDT, 3,3-3,2-1,1; endrin, 0,56; dieldrin, 1,1; aldrin, 1,1; dimetoato, 2,2-0,56; heptaclor, 2,2-0,56, paration, 1,1- 
0,56; toxafeno, 3,3-1,7-2,2; endosulfan, 0,84; forate, 1,1-2,2, disulfo ton, 1,1-2,2. Conclui o autor que os inseticidas nas formulações granuladas aplicadas na superfície do solo foram mais eficientes que em pulverização, e que os inseticidas endrin', paration e DDT, nas maiores do sagens foram os mais eficientes na redução do dano da lagarta elasmo. Ds inseticidas, quando aplicados em pulverização, foram mais eficientes quan do submetidos à pressão de 30 e 40 p.s.i e na dosagem de 46 a 185 litros/ ha.

CORSEUIL e TERHORST (1971), trabalhando com carbaril, dime toato, DDT, endrin, lindane e fosfamidon, nas dosagens de 2.160; 300; 1.800; 600; 450 e 300 gramas de i.a/ha, respectivamente, obtiveram melho res resultados no controle da elasmo com endrin, DDT e lindane, nessa or dem decrescente, em culturas de soja (Glicyne max), tendo sido os produtos aplicados em pulverização na emergéncia das plantas.

Visando estudar o efeito de diversos inseticidas sobre a lagarta elasmo, e na germinação de semente de milho (zea mays), CAMPOS (1972), no Valley Sayan (Peru), testou vários inseticidas impregnando-os às sementes, e concluiu que os melhores tratamentos no controle da lagarta elasmo foram: carbofuran PM, $6,0 \mathrm{~g}$ i.a/kg de semente, metamidofos, 3,0 g i.a/kg de semente, monocrotofos $2,4 \mathrm{~g}$ de i.a/kg de semente.

Todavia, os inseticidas metomil, 5,$40 ; 2,88 \mathrm{~g}$ de i.a/kg de semente, metamidofos, 4,20; 3,60;,7,60 g de i.a/kg de semente, fentoato, $4,20 \mathrm{~g} \mathrm{i.a/kg} \mathrm{de} \mathrm{semente,} \mathrm{e} \mathrm{carbaril,} 3,40 \mathrm{~g} \mathrm{i.a/kg}$ de semente, causaram 
.13.

sensível redução na germinação, apesar de controlarem eficientemente lagarta Elasmo, exceção feita a fentoato, optunal e carbaril.

Na cultura de sorgo sacarino, HENDERSON et alii (1973) tes taram os inseticidas aldrin $10 \mathrm{G}, 1,1$; 2,2; carbofuran $10 \mathrm{G}, 1,1, \quad 2,2$, 3,3; 4,5; diazinon $14 \mathrm{G}, 1,1 ; 2,2$; monocrotofos $10 \mathrm{G}, 2,0 \mathrm{em} \mathrm{kg} \mathrm{1.a/ha,}$ destacando-se o carbofuran, diazinon e monocrotofos como mais eficientes que aldrin, quando aplicados na superfície do solo.

A adição de substâncias que melhoram a aderéncia dos produ tos inseticidas à semente, tem sido testada conforme trabalho desenvolvido por YOKOYAMA e NAKANO (1977), que testaram o carbofuran em tratamento de sementes de arroz, nas dosagens de $350 \mathrm{~g} \mathrm{e} 375 \mathrm{~g}$ de i.a/50 kg de semente, sendo o inseticida aderido à semente com adesivo "mowiol" à base de P.V.A. e melaço. O carbofuran foi superior ao aldrin, ambos empregados na dosa gem de $350 \mathrm{~g} \mathrm{i.a/50} \mathrm{kg} \mathrm{de} \mathrm{semente.}$

Analisando o efeito da irrigação, cultivo mínimo e cultivo convencional, na cultura de milho Zea mays, associados a inseticidas, ALL e GALLAHER (1977) concluiram que os produtos mais eficientes dentre os di versos testados foram forate, terbufos, carbofuran, na dosagem de 170,8 g i.a/1000 m, tendo-se obtido maiores reduções no dano da lagarta Elasmo quando associados à técnica do cultivo mínimo.

o controle da lagarta elasmo foi pesquisado por DICKSON et aliz (1978), na Flórida, em cultura de milho, que concluiram que os produ tos: fonofos $10 \mathrm{G}$, thimet $15 \mathrm{G}$, carbofuran $15 \mathrm{G}$, na dosagem de $2,24 \mathrm{k}$ 
.14 .

i.a/ha, foram os mais efetivos na redução de plantas atacadas pela lagar ta elasmo, quando aplicados numa faixa de $17 \mathrm{~cm}$ incorporado ao solo 5,0 $\mathrm{cm}$ acima da semente.

Resultados semelhantes foram obtidos por ALL (1978), na Georgia, em solo argiloso, destacando-se, em ordem decrescente de eficiên cia, os inseticidas: carbofuran $10 \mathrm{G}$, clorpirifos etil $15 \mathrm{G}$, fensulfotion $15 \mathrm{G}$, terbufos $15 \mathrm{G}$, na dosagem de $2,24 \mathrm{~kg} \mathrm{i.a/ha,} \mathrm{e} \mathrm{que} \mathrm{uma} \mathrm{intensa} \mathrm{mor}$ talidade de plantas ocorreu 7 dias após a emergéncia das plàntulas.

Experimentos conduzidos por ALL et alii (1979), tabela 1, durante 05 anos de 1974-78, demonstraram que a aplicação em faixa, no ato da semeadura, de clorpirifos e fonofos, na dosagem de $0,22 \mathrm{~kg} \mathrm{i.a/1000} \mathrm{me}$ tros lineares, deram um satisfatório controle da lagarta elasmo, em milho Zea mays, em várias datas de plantio, em vários tipos de solos, e nos cul tivos convencionais ou minimo; carbofuran, isofos e terbufos também con trolaram as infestações, mas com uma eficiència média menor. Na dosagem

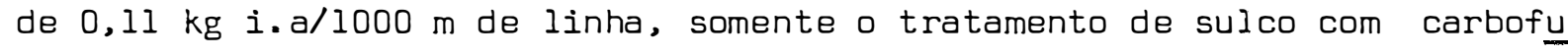
$r$ an foi efetivo. 
.15 .

Tabela 1. Eficiéncia de inseticidas granulados aplicados no solo em fa1. $x a$, na dosagem de 0,22 kg i.a/1000 metro linear, para controle da lagarta elasmo em milho, no período de 74/78. Geórgia. Mo dificada de ALL et alii, 1978.

\begin{tabular}{lccc}
\hline INSETICIDA & $\%$ controle & C.V.\% & $N^{8}$ de ensaios \\
\hline acefate & 42,0 & 77,0 & 5 \\
aldicarb & 20,9 & 122,0 & 5 \\
carbofuran & 76,1 & 41,0 & 18 \\
clorpirifos etil & 81,8 & 13,0 & 11 \\
diazinon & 43,9 & 39,0 & 3 \\
disulfoton & 25,2 & 170,0 & 4 \\
etoprop & 17,7 & 169,0 & 13 \\
fonofos & 74,2 & 16,0 & 3 \\
metomil & 69,9 & 31,0 & 8 \\
forate & 45,8 & 99,0 & \\
\hline
\end{tabular}

Na cultura de arroz de sequeiro, DOMICIANO (1979), em Pon ta Grossa (PR), utilizou os seguintes produtos: acefate 75 PM, $1,125 \mathrm{~kg}$ i.a/ha; diazinon $60 \mathrm{E}, 0,48 \mathrm{~kg} \mathrm{i.a/ha;} \mathrm{endrin} 20 \mathrm{E}, 0,3 \mathrm{~kg} \mathrm{i.a/ha;} \mathrm{clorpí}$ r ifos etil $48 \mathrm{E}, 0,729 \mathrm{~kg}$ i.a/ha; carbofuran $75 \mathrm{PM}, 0,750 \mathrm{~kg} \mathrm{i.a/ha,} \mathrm{em}$ pulverização na superfície do solo, em faixa, após o aparecimento dos pré meiros sintomas; oxamil $10 \mathrm{G}, 2,0 \mathrm{~kg}$ i.a/ha, carbaril 7,5 G, 1,l kg i.a/ ha, diazinon $14 \mathrm{G}, 1,4 ; 2,1 \mathrm{~kg} \mathrm{i.a/ha;} \mathrm{carbofuran} 35 \mathrm{FW}, 0,525 \mathrm{~kg}$ 1.a/100 kg de semente; acefate 75 PM, $1,12 \mathrm{~kg}$ i.a/35 kg de semente, aldrin $40 \mathrm{~S}$, $0,160 \mathrm{~kg} \mathrm{i.a/60} \mathrm{kg} \mathrm{de} \mathrm{semente,} \mathrm{em} \mathrm{tratamento} \mathrm{de} \mathrm{semente.} \mathrm{Desses,} \mathrm{destê}$ cou-se o carbofuran em tratamento de semente como majs eficiente na redu 
.16.

ção do dano da lagarta Elasmo, tendo ocorrido uma redução superior a $80 \%$ no "stand" dos. demais tratamentos.

MARTINS et alii (1980) observaram que a utilização de inse ticidas em tratamento de sementes de arroz de sequeiro, aldrin $P$ e carbofu ran PM, permitiram um maior número de perfilhos $/ \mathrm{m}^{2}$, controlando cupins e lagarta Elasmo.

BERTELS (1980) enumera os seguintes métodos de controle da lagarta E. lignosellus: método ecológico (época adequada de semeadura em função das precipitações); método agrotécnico (espaçamento da cultura $x$ in festação da lagarta elasmo) e método químico (utilização de inseticidas: clorpirifos etil LVC na superfície do solo e carbaril PM no sulco e em co bertura). Destaca o autor que ocorreu menior número de plantas danificadas nos tratamentos com maiores espaçamentos e não ocorreu diferença de infes tação entre os tratamentos onde se utilizou inseticidas.

Diversos inseticidas foram utilizados por GOMES (1980) em tratamento de sementes de trigo. Ele observou que o acefate PS, na pro porção de 1500 gramas de i.a/100 kg de semente de trigo, quando utilizado na época normal foi fitotóxico, e quando a semeadura foi realizada na épo ca de seca foi altamente fitotóxico, mesmo nas dosagens mais baixas (750

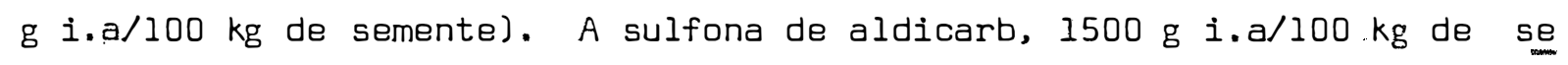
mentes, apresentou fitotoxidade média e retardou a germinação em 13 dias.

Em relação ao controle, o produto que se mostrou eficiente e pouco fitotóxico foi o carbofuran $F$, na dose de $700 \mathrm{~g} \mathrm{i.a/ha.}$ 


\section{MATERIAIS E METODOS}

Ds experimentos relatados neste trabalho foram desenvolvi dos em laboratório e campo, no Departamento de Entomologia da Escola Superior de Agricultura "Luiz de Queiroz", da Universidade de São Paulo, em Pi racicaba, SP, no período de junho de 1979 a outubro de 1980.

\subsection{Criação Massal}

\subsubsection{Obtenção dos insetos no campo}

Para início da criação massal de E. lignosellus, as larvas foram coletadas em culturas de trigo nos Municípios de Paranapanema e Rio Claro, SP, e colocadas em trigo recém-germinado, para transformação em pu pas, em vaso de alimentação.

3.1.2. Manuseio e sexagem das pupas

Decorrido o período necessário para o completo desenvolvi- 
.18.

mento larval e início"do pupal, os casulos contendo as pupas, juntamente com a camada superficial de areia, foram retirados dos vasos de alimenta ção e separadas com o auxílio de uma peneira de malha com $0,5 \mathrm{~cm}$ de diàmetro. Os casulos obtidos eram tratados com solução de hipoclorito de sódio à $5 \%$ por 1,0 minuto. As pupas separadas dos seus casulos eram lavadas em água corrente, depositadas em placas de Petri, com o fundo forrado com papel toalha umedecido, e sexadas com auxílio de binocular de 40 aumentos. Após a identificação dos sexos as pupas foram mantidas nas placas de Petri para emergència dos adultos.

\subsubsection{Manuseio e alimentação dos adultos}

Os adultos emergidos eram transferidos para o recipiente co letor de postura. Este tubo consistía num cilindro plástico, com $19 \mathrm{~cm}$ de diàmetro e $19 \mathrm{~cm}$ de altura (Figura la). A parte superior do tubo foi parcialmente fechada com uma placa de vidro circular de $21 \mathrm{~cm}$ de diámetro, pos suindo uma abertura concèntrica de $8,8 \mathrm{~cm}$ de diàmetro, por onde eram introduzidos e retirados os insetos, (10 casais/recipiente coletor de postu ra), o alimento e o suporte do papel para postura (Figura lb). Este consti tuía-se de uma lata de guaraná colada perpendicularmente numa placa de vidro circular, e a superfície externa da lata recoberta com uma folha de pa pel guardanapo azul, "Snobb", onde as mariposas faziam a postura. A alimen tação do adulto foi fornecida através de chumaço de algodão embebido em so lução de sacarose à $20 \%$. 


\subsubsection{Obtenção e manuseio de ovos}

O papel guardanapo com ovoposição era depositado no incubador de ovos (Figura lc), de $13 \mathrm{~cm}$ de altura e $13 \mathrm{~cm}$ de diàmetro. Para fechar o incubador, colocava-se entre o bordo do incubador e a tampa, folha dupla de papel guardanapo levemente umedecido, encaixando-se a tampa com pressão. Após essa operação, os ovos eram postos em estufa altemperatura $27 \pm 50 \mathrm{C}$ ) para incubação imediata, ou em geladeira (temperatura 100 C) para retardar a incubação, quando necessārio.

\subsubsection{Preparação e manuseio do substrato e das lagartas}

\subsubsection{Preparação do vaso de alimentação (Figura ld)}

Adicionou-se $1,5 \mathrm{~kg}$ de solo peneirado num tubo cilíndrico de $22,2 \mathrm{~cm}$ de altura e $14,0 \mathrm{~cm}$ de diämetro. Na superfície do solo, colocou-se folha dupla de papel guardanapo e sobre essa adicionou-se 40,0 gra mas de semente de trigo ( $80 \%$ de germinação), tratada com o fungicida dicloran PM 50\%, : na proporção de 0.5 grama $i . a / 1,0 \mathrm{~kg}$ de semente. Posteriormen te, as sementes foram cobertas com camada de areia grossa de $3,0 \mathrm{~cm}$ de altura. Após a germinação, 5 dias após a semeadura, os tubos foram infestados com as lagartas, e a cada 7 dias umedeceu-se o solo por infiltração, atrá vés dos orifícios (em nümero de 6 ) do fundo do vaso de alimentação, colo cando-se os mesmos sobre uma lámina de $4.0 \mathrm{~cm}$ de água, tomando-se o cuidado para que a camada de areia superficial não fosse umedecida. 
.20 .

Figura 1: a - Recipiente coletor de postura.

b - Suporte do papel para postura.

c - Vaso incubador de ovos.

d - Vaso de alimentação de lagartas de Elasmopalpus lignosellus. Piracicaba, novembro de 1980. 


\subsubsection{Manuseio e alimentação das lagartas}

Após a eclosão, as lagartas que encontravam-se no incubador de ovos (Figura lc) eram removidas com auxílio de um pincel de pêlo de camelo, e transferidas para os vasos de alimentação na proporção de 25 lagartas/vaso, até que completasse o ciclo larval (12 a 15 dias).

\subsection{Dados Biológicos}

A biologia de E. lignosellus foi desenvolvida sob condições controladas de laboratório, à temperatura de $27 \pm 5^{\circ} \mathrm{C}$ e umidade relativa de $70 \pm 10 \%$.

\subsubsection{Ovo}

Para observação da viabilidade total e diäria dos ovos, fo ram examinadas parte das posturas diárias, dos 30 casais, coletadas durante o período de ovoposição das mariposas.

Os ovos foram postos nos incubadores e examinados ao final do $3^{8}$ dia, para anotações das larvas eclodidas.

\subsubsection{Lagartas}

Para determinação dos parámetros biológicos das lagartas foi preciso estabelecer que todas possuiam crescimento uniforme, quando submeti 
das às mesmas condições de temperatura, umidade, espaço e alimentação.

\subsubsection{Experimento para determinação do crescimento de lagartas E. lignosellus}

Infestaram-se 40 vasos de alimentação, igualmente preparo dos, com 25 lagartas/vaso. Estes vasos foram colocados em estufa regulada com 12 horas luz +12 horas de escuro e temperatura de $27 \pm 5^{\circ} \mathrm{C}$. Nos dias subsequentes, a partir do $1^{8}$ dia após a infestação, as larvas de 2 vasos/dia foram retiradas, lavando-se a areia com água sanitária diluf́da na proporção de $1: 1$. As larvas coletadas diariamente eram fixadas em ägua quente, medidas as cápsulas cefálicas ao microscópio estereoscópio Wild M4, com lente micrométrica e conservadas posteriormente em álcool 70\%, e no final do $14^{8}$ dia encerrou-se o ensaio utilizando 28 tubos abertos.

Nas leituras diárias foram identificadas as mudanças de ecdise, através de diferença de tamanho da cápsula cefálica dos indivíduos amostrados de mesma idade. Após a identificação do tamanho máximo e míni mo da cápsula cefálica referente a cada ínstar, ordenou-se no sentido cres cente todos os dados de cápsula cefálica de cada lagarta,pareados com suas respectivas idades. O tamanho máximo e mínimo da cápsula fol comparado com esses dados. Ordenados dessa forma, determinou-se a frequência de in divíduo pertencente a cada ínstar larval, calculando-se os valores mádios da cápsula e respectiva duração. 


\subsubsection{Pupa}

Pesaram-se 39 pupas em balança analítica, marca METTLER-H7. 3 dias após a pupação. Para sexagem examinou-se 126 pupas sob miscroscópio estereoscópio.

\subsubsection{Adulto}

Para obtenção dos dados bionómicos do adulto distribuiram- se 30 casais de mesma idade em 3 tubos coletores de postura, ou seja, 10 casais/tubo coletor de postura. Foram anotados e coletados o número de ovos postos/tubo coletor/dia, o sexo e dia da morte da mariposa, sendo a alimentação do adulto renovada a cada 3 dias.

\subsection{Avaliação do Dano}

Ensaio visando à determinação do nūmero de plantas danificadas por Tagartas de E. lignosellus

Este ensaio foi conduzido em casa-de-vegetação sendo que ca da tratamento, relacionado na tabela 2 , tinha 10 repetições. 
Tabela 2 - Relação das espécies vegetais testadas, nome das cultivares e $n^{8}$ de plantas/parcela.

TRATAMENTO CULTIVAR
PARCELA
A. Milno
Centralmex
10
Zea mays $L$.
B. Sorgo sacarino
Brandes
15
Sorghum bicolor L.
C. Trigo
IAC- 5
30
Triticum aestivum L.
D. Arroz
IAC- 47
30
Oryza sativa L.
E. Soja
Santa Rosa
10
Glycine max Merrill
F. Feijão
Carioca
10
Phaseolus vulgaris L.

As sementes foram distribuídas na superfície do solo conti do em sacos plásticos pretos de $25 \mathrm{~cm}$ de diāmetro e $30 \mathrm{~cm}$ de profundidade. e cobertas com camadas de $3,0 \mathrm{~cm}$ de areia grossa. No centro do saco plástico colocou-sẹ, verticalmente, um tubo plástico de $1 / 2$ polegada e $27,0 \mathrm{~cm}$ de comprimento, aberto nas duas extremidades, ficando uma delas fora do so lo para irrigação. Dez dias após a semeadura efetuou-se o desbaste,deixan do o número de plantas por parcela conforme relacionados na Tabela 2. Em seguida colocou-se 2,0 larvas recém-eclodidas por parcela, e 30 dias após a infestação avaliou-se o número de "coração morto" (PD) e o nūmero de pupas de cada parcela (P). 
3.4. Preparação e Materiais Utilizados nos Ensaios Preliminares de Con trole Quĩmico e Controle com Irrigação

\begin{abstract}
As caixas plásticas utilizadas nesses experimentos possuiam $40 \times 30 \times 12 \mathrm{~cm}$ de dimensões e orifícios no fundo para drenagem do excesso de água. Elas recebiam o solo e a $7,0 \mathrm{~cm}$ de profundidade, foi colocado um tubo de 1/2", em forma de "L", $\operatorname{com} 27+12 \mathrm{~cm}$ de comprimento, possuindo o segmento mais longo a extremidade fechada e lateralmente 10 orifícios para saída d’água. Esse tubo constituiu-se no cano de irrigação, com a finalidade de suprimento hídrico naqueles tratamentos os quais näo receberam irrigação por aspersão. As caixas, assim preparadas e após receberem a semea dura, constituíram-se nas parcelas experimentais.
\end{abstract}

\title{
3.5. Efeito da Frequēncia de Irrigação. por Aspersão. Sobre Lagartas
} E. lignosellus

Este experimento foi conduzido com 5 tratamentos e 4 repeti ções, e cada parcela constou de uma caixa plástica com 1,00 metro linear de cultura e 90 plantas aproximadamente.

Após a germinação, adicionou-se uma camada de $2,0 \mathrm{~cm}$ de areia, fazendo-se a infestação com 10 lagartas de $I^{8}$ instar/caixa, 40/tra tamento.

Nas irrigações por aspersão utilizou-se aspersores de jar dins, deixando-os ligados até que fosse fornecida a quantidade de àgua cor respondente a cada tratamento, relacionados na Tabela 3, medida através de 
pluviómetros feitos com latas de capacidade para 1,0 litro.

Tabela 3 - Tratamentos, intervalos entre as irrigações, número de irrigações efetuadas, coluna de água, em mm/irrigação e total fornecí do no período do ensaio.

\begin{tabular}{|c|c|c|c|c|}
\hline $\begin{array}{l}\text { TRATA- } \\
\text { MENTD }\end{array}$ & $\begin{array}{l}\text { INTERVALO } \\
\text { ENTRE } \\
\text { IRRIGAÇAO } \\
\text { POR ASPER } \\
\text { SÄO (DIAS) }\end{array}$ & $\begin{array}{c}N^{8} \text { DE } \\
\text { IRRIGAÇÃO }\end{array}$ & $\begin{array}{c}\text { COLUNA OE AGUA } \\
\text { FORNECIDA POR } \\
\text { ASPERSAOO } \\
(\mathrm{mm})\end{array}$ & $\begin{array}{l}\text { TOTAL DO } \\
\text { PERIODO } \\
(\mathrm{mm})\end{array}$ \\
\hline A & 3 & 10 & 5 & 50 \\
\hline$B$ & 6 & 5 & 10 & 50 \\
\hline C & 10 & 3 & 17 & 50 \\
\hline$D$ & 15 & 2 & 25 & 50 \\
\hline$E$ & Testemunha & 0 & 0 & 0 \\
\hline
\end{tabular}

Nos tratamentos onde ocorria deficiēncia hídrica às plantas antes de uma nova irrigação por aspersão, fazia-se a irrigação por infil tração pelos tubos, tomando-se o cuidado de não umedecer a superfúcie. Pro cedia-se dessa maneira porque verificou-se que a sobrevivência das larvas de E. lignosellus era afetada pela umidade da camada superficial do solo. Após as infestações, as caixas eram mantidas em casa-de-ve getação, sendo retiradas somente para as irrigações por aspersão e, decor ridos 33 dias da infestação, fez-se a avaliação. 


\subsection{Dados Referentes à Cultura dos Ensaios de Controle}

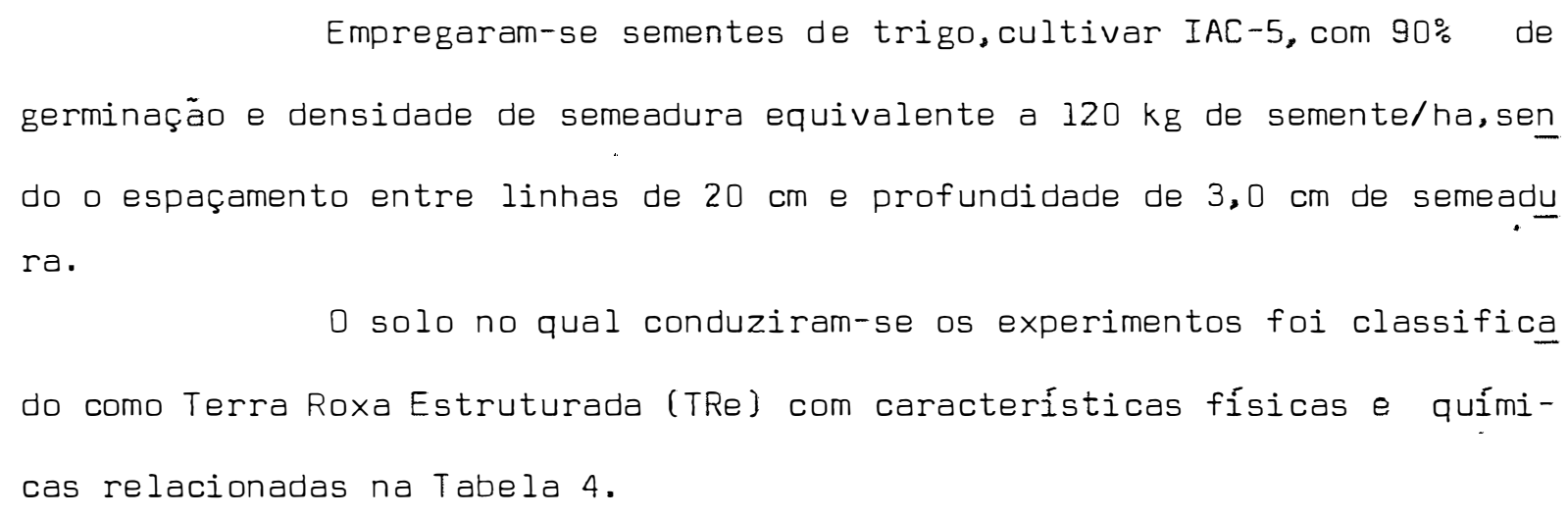
ra.

O solo no qual conduziram-se os experimentos foi classifica do como Terra Roxa Estruturada (TRe) com características físicas e químicas relacionadas na Tabela 4.

Tabela 4 - Análise de terra do local do experimento e do solo acondicionado nas caixas plásticas. Piracicaba, SP., 1980.

\begin{tabular}{|c|c|c|c|c|c|c|c|}
\hline \multirow[b]{2}{*}{$\mathrm{pH}$} & \multirow{2}{*}{$\begin{array}{l}\text { Carbono } \\
\text { Orgänico } \\
(\%)\end{array}$} & \multicolumn{2}{|c|}{ TEOR TROCÁVEL EM } & \multicolumn{3}{|c|}{ MILIEQUIVALENTES/100 g DE } & \multirow{2}{*}{$\begin{array}{c}\text { TERRA } \\
\text { Nitro- } \\
\text { génio } \\
\mathrm{H}^{+}\end{array}$} \\
\hline & & $\begin{array}{c}\text { Fósforo } \\
\mathrm{PO}_{4}^{-3}\end{array}$ & $\begin{array}{c}\text { Potássio } \\
\mathrm{K}^{+}\end{array}$ & $\begin{array}{c}\text { Cálcio } \\
\mathrm{Ca}^{++}\end{array}$ & $\begin{array}{c}\text { Magnésio. } \\
\mathrm{Mg}^{++}\end{array}$ & $\begin{array}{l}\text { Aluminio } \\
\mathrm{Al}^{+3}\end{array}$ & \\
\hline 5,7 & 0,88 & 0,36 & 0,30 & 3,50 & 0,31 & 0,80 & 4,15 \\
\hline
\end{tabular}

Adubação utilizada:

$$
\begin{aligned}
& \text { semeadura } 50 \mathrm{~kg} \text { de } \mathrm{N} / \mathrm{ha}, \\
& 30 \mathrm{~kg} \text { de } \mathrm{P}_{2} \mathrm{O}_{5} / \mathrm{ha}, \\
& 20 \mathrm{~kg} \text { de } \mathrm{K}_{2} \mathrm{O} / \mathrm{ha} .
\end{aligned}
$$


3.7. Tipos de Aplicação e Distribuição dos Inseticidas Utilizados nos Ensaios de Controle

\subsubsection{Pulverização do Sulco (TS)}

Utilizaram-se inseticidas com as formulações, concentrado $\underline{\underline{e}}$ mulsionável (EC), pó molhável (PM), pó solúvel (PS) e Flowable (F). Os produtos comerciais foram diluídos à base de 400 litros de água por hectare e pulverizados sobre o sulco e sementes com pulverizador de pressão constante, 30 libras, equipado com bico em leque 8004 .

\subsubsection{Tratamentos de sementes (ST)}

$$
\text { Para as sementes tratadas com formulaçōes "flowable" (F). }
$$

e concentrado emulsionável (EC), utilizaram-se sacos plásticos para homogeneização. Para o tratamento das sementes com as formulações pó molhävel (PM) e pó solúvel (PS), as sementes foram levemente umedecidas para aderência do pó.

Após os tratamentos, as sementes foram secadas sobre plästi co e distribuídas no sulco através de tubos de ensaio graduados.

\subsubsection{Granulados no Sulco (GS)}

As formulações granuladas (G) foram pesadas em balança analitica para dosagem por metro linear da cultura e distribuídas no sulco através de pequenos tubos de vidro. 


\subsection{Controle}

Subdividiu-se esse ensaio em duas fases: a primeira denomi nada preliminar e seletiva I e II, e a segunda confirmativa.

\subsubsection{Experimento fase preliminar e seletiva I}

Utilizaram-se diferentes inseticidas, aplicados no sulco de semeadura, visando o controle de lagartas de E. lignosellus e o efeito dos mesmos na germinação.

Este experimento foi conduzido com 10 tratamentos e 3 repe tições, sendo a parcela experimental constituída por uma caixa plástica com 1,0 metro linear de sulco, distribuindo-se 90 semente por parcela. As dosagens dos inseticidas e o tipo de aplicaçào estão relacionados na Tabela 5 .

Tabela 5 - Relaçào dos inseticidas empregados e suas respectivas dosagens em gramas de ingrediente ativo por hectare e tipo de aplicaçāo.

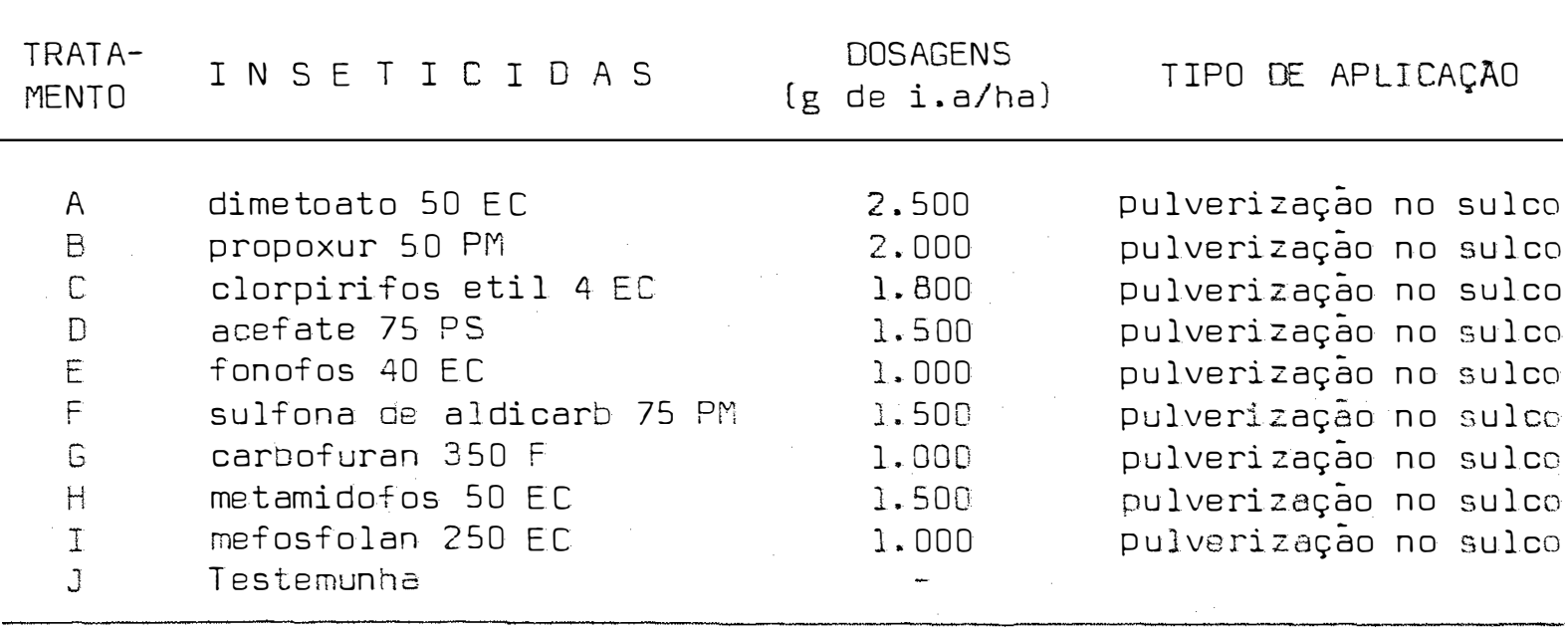


A infestação foi efetuada colocandorse 30 ovos/parcela. 5 dias após a germinação; as parcelaś mantidas em casa de vegetação e irriga das através dos tubos subterráneos.

A avaliação do "stand" inicial foi efetuada 5 dias após a germinação e a avaliação do nümero de plantas danificadas 28 dias apōs a infestação.

\subsubsection{Experimento fase pretiminar e seletiva II}

Esse ensaio preliminar foi instalado com diferentes inseticidas, em tratamento de semente, visando o controle de lagartas de E. lignosellus e efeito na germinação da semente de trigo. Constou de 7 tratamentos e 3 repetições, sendo a parcela experimental constituída por uma caixa plástica com l,0 metro linear de sulco. As sementes tratadas, 90 por parcela, foram distribuidas nos sulcos, sendo irrigadas pelo sistema descrito e mantidas no interior da casa-de-vegetação. Os produtos utilizados estão relacionados na Tabela 6 .

Tabela 6 - Relação dos inseticidas e dosagens em gramas do ingrediente ati vo por kg de semente.

\begin{tabular}{|c|c|c|}
\hline TRATAMENTO & INSETICIDA & $\begin{array}{l}\text { DOSAGEM } \\
\text { (g de } \begin{array}{l}i . a / 120 \\
\text { semente) }\end{array}\end{array}$ \\
\hline A & clorpirifos etil $4 E C$ & 1.800 \\
\hline$E$ & metamidotos 60 EC & 1.500 \\
\hline c & oropoxur 50 PM & 2.000 \\
\hline [ & acefate 75 PS & 1.500 \\
\hline$\Xi$ & sulfona de aldicare 75 PM & 1.500 \\
\hline$F$ & carbofuran $350 \mathrm{~F}$ & 1.000 \\
\hline 6 & Testemunhe & - \\
\hline
\end{tabular}


A infestação foi efetuada colocando-se 30 ovos/parcela, 11 dias após a germinação. A avaliação do "stand" inicial foi efetuada 5 dias após a germinação, e o número de plantas danificadas, 22 dias após a infestação.

\subsubsection{Experimento confirmativo}

Experimento visando o controle de lagartas $E$. lignosellus na cultura do trigo (Triticum aestivum)

Este ensaio foi conduzido em casa-de-vegetação (piso de ter ra), com 16 tratamentos e 4 repetições. As parcelas experimentais foram constituídas por 1,0 metro linear de cultura, com as respectivas linhas de bordadura, espaçadas de $20 \mathrm{~cm}$, locadas ao acaso no interior da casa-de-vegetação, e tendo-se gasto 2,4 gramas de semente por metro linear, ou seja, $120 \mathrm{~kg}$ de sementes/ha\}.

Após a distribuição das sementes,o solo foi irrigado artıfi cialmente, repetindo-se essa operação somente 30 dias depois.

As infestações foram efetuadas com 10 larvas recém eclodidas por parcela, mais a liberação de 50 casais de mariposas no interior da casa-de-vegetação 6 dias após a germinação.

Os inseticidas utilizados nesse experimento, bem como suas cosagens, estão relacionados na Tabela 7. 


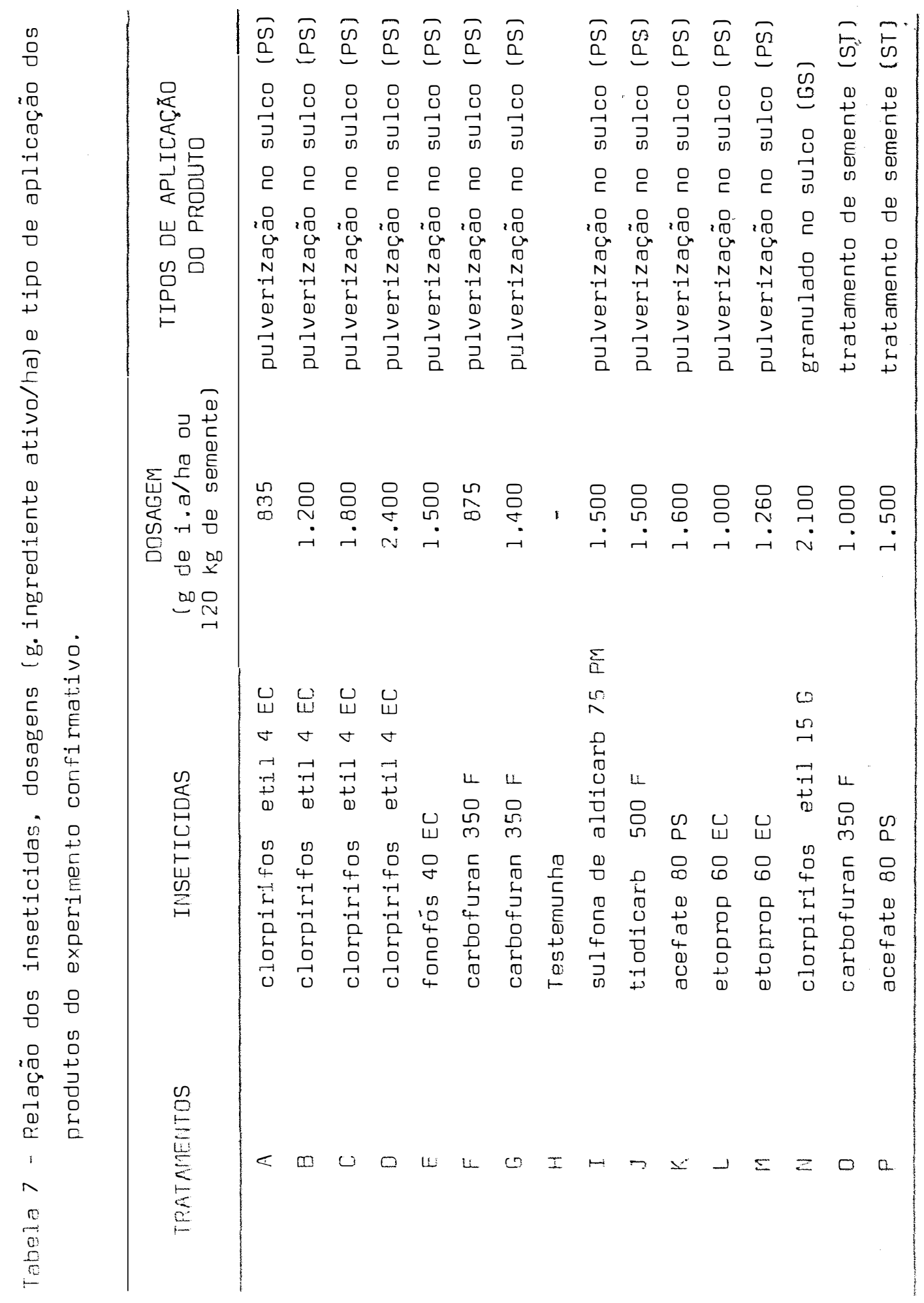


3.9. Da análise estatîstica

Ds ensaios de avaliação de dano, irrigação e controle fo
ram delineados segundo os critérios estatísticos dos experimentos inteira
mente casualizados. Os dados obtidos nos experimentos foram transformados
em $\sqrt{x+0,5}$ e as médias transformadas foram comparadas através do Teste
de Tukey à nível de $5 \%$.




\section{RESULTADOS E DISCUSSAOO}

\section{1. Dados Biológicos}

\subsection{7. Ōyo}

as ovos de E. Kignascllus medem cerca de $0,60 \mathrm{~mm}$ de comprí mento por 0,36 mm de diámetro, pouco diferindo dos resultados obtidos por LEUCK (1966), de $0,61 \times 0,37 \mathrm{~mm}$; são semi-elípticos possuindo o córion hia lino finamente reticulado. Nas primeiras 12,0 horas após a postura são de cor branco peŕola, tornando-se róseo escuro próximos à eclosão. Segun do HAYWARD (1943), eles são esbranquiçados, Iigeiramente esverdeados, quan do recém-postos, depois rosados e pouco antes da lagarta nascer são amare lados. São fixados ao substrato por secreção mucilaginosa hialina, que endurece horas após a postura.

D período de incubação é de 3,0 dias à temperatura de $27 \pm 5^{\circ} \mathrm{C}$ e U.R. $70 \pm 10 \%$. Fara DUPREE (1965) foi de 4.0 dias à tempera tura de $25 \pm E^{\circ}[$ e U.R. de $70 \%$ e fara LEUCK (1966) foi de 3,0 dias.

A Tabela 8 mostre a viabilidade dos ovos considerando todo o periodo de postura, que é es 84\%, em média. 
.35 .

Tabela 8. Viabilidade dos ovos por postura de 30 fêmeas de

E. lignosel lus, temperatura $27 \pm 5^{\circ} \mathrm{C}$ e U.R. $70 \pm 10 \%$. Piracicaba, SP. 1980.

\begin{tabular}{cc}
\hline POSTURA & VIABILIDADE $(\%)$ \\
\hline $1 !$ & 87,0 \\
$2 !$ & 93,0 \\
$3 \cdot$ & 94,0 \\
$4 !$ & 91,0 \\
$5 !$ & 89,0 \\
6! & 84,0 \\
$7 !$ & 50,0 \\
\hline MEDIA GERAL & $84,0 \%$ \\
\hline
\end{tabular}

\subsubsection{Lagarta}

A lagarta recém-eclodida liberta-se do cörio através de um orifício que faz destruindo parte dele, normalmente no pólo superior do ovo; após a vinda ao meio externo, abriga-se imediatamente no solo. Quando posta na planta, desce por meio de um fio de seda até a superfície do solo, procura o coleto da planta e enterra-se na sua proximidade a $1,0 \mathrm{~cm}$ de pro fundidade. Em seguida tece, com fio de seda e areia, um tubo aderido à plan ta no interior do qual se abriga quando em repouso; com a morte da pjántula a lagaria deixa o tubo de seda procurando outra planta. Após o ültimo instar larval, já na fase de pré-pupa, a lagarta tece o casulo no interior do qual ocorre a transformação em pupa. 


\subsubsection{Descrição da lagarta.}

Logo após a eclosão, as lagartas são róseas com uma $11 \underline{\text { as }}$ ta vermelha no dorso algumas vezes interrompida. Lagartas de maior idade são de cor cinza a cinza esverdeado ou arroxeada; a cabeça pode ser de mar rom escuro a castanho. Em todas as fases elas são extremamente ágeis, sal tando, caminhando para a frente ou para trás, quando tocadas.

\subsubsection{Desenvolvimento larval}

A Tabela 9 mostra os dados do desenvolvimento larval de $E$. lignoscllus obtidos através de medições da largura da cápsula cefálica das lagartas, que permitiram a obtenção da média da razão de crescimento, que foi de 1,35, sendo praticamente constante durante todo o desenvolvimento larval. Segundo a regra de Dyar (1890) citada por GALLO et aizi, "as cápsulas cefálicas das lagartas de lepidópteros crescem em progressão geomé trica; aumentando em largura a cada ecdise, numa relação que é constante para cada espécie e, em média 1,4". LEUCK (2.966) determinou a razão do crescimento da Iagarta elasmo, que foi de 1,44. Considerando-se esses valo res, pode-se admitir que a metodologia adotada para determinação dos parámetros larvais foì satisfatórìa. 
Tabela 9. Largura média da cápsula cefálica, em mn, razão média de crescí mento da cápsula cefálica, e duração médias, em dias, de cada instar larval de $E$. lignosellus. Temperatura $27 \pm 5^{\circ} \mathrm{C}$ \& U.R. $70 \pm 10 \%$. Piracicaba, SP., julho 1980.

\begin{tabular}{cccc}
\hline $\begin{array}{c}\text { Instar } \\
n^{8}\end{array}$ & $\begin{array}{c}\text { Largura da } \\
\text { cápsula célica } \\
\text { (mm) }\end{array}$ & $\begin{array}{c}\text { Razão de } \\
\text { crescimento }\end{array}$ & $\begin{array}{c}\text { Duração do } \\
\text { Instar } \\
\text { (dias) }\end{array}$ \\
\hline lạva recém-eclodida & $0,185 \pm 0,015$ & 1,13 & $1,30 \pm 0,34$ \\
1 & $0,210 \pm 0,029$ & 1,52 & $1,59 \pm 0,61$ \\
3 & $0,320 \pm 0,063$ & 1,65 & $2,10 \pm 0,74$ \\
4 & $0,530 \pm 0,045$ & 1,36 & $2,39 \pm 1,23$ \\
5 & $0,720 \pm 0,071$ & 1,21 & $0,80 \pm 0,96$ \\
6 e pré-pupa & $0,870 \pm 0,034$ & 1,35 & $2,56 \pm 1,56$ \\
\hline
\end{tabular}

Pelos dados da Tabela 9, verifica-se que a duração do ciclo larval foi de $11,0 \pm 4,00$ dias, à temperatura de $27 \pm 5^{\circ} \mathrm{C}$, distribuidos entre 6 instares. O valor encontrado por LEUCK (1966) para a duração do ciclo larval foi de 19,6 \pm 2,0 dias, distribuidos entre 6,0 ínstares, para DUPREE (1965) foi de 33,0 dias, a uma temperatura de $25 \pm 6{ }^{\circ} \mathrm{C}$.

A viabilidade larval determinada foi de $72,8 \%$ ou seja, de 250 lagartas colocadas em 10 tubos de alimentação resultaram em 182 pupas, enquanto que SAUER (1939) havia determinado uma viabilidade larval de 1.5\%, quando as lagartas eram manipuladas diariamente e alimentadas com fo Iha de arroz. 
.38 .

\subsubsection{Pré-pupa}

As lagartas nessa fase caracterizam-se por serem mais lan tas, apresentarem-se mais curtas e com o corpo mais volumoso. A duração dessa fase encontra-se em conjunto com a do $6^{8}$ ínstar larval, que é de

$2,56 \pm 5,0{ }^{\circ} \mathrm{C}$. DUPREE (1965) obteve 8,8 dias à temperatura de $25 \pm 6{ }^{\circ} \mathrm{C}$ para a mesma fase.

\subsubsection{Pupa}

E do tipo obtecta, tegumento esclerosado, inicialmente ver de claro, evoluindo para marrom escuro, segmentações bem nítida, com arti culação nos últimos segmentos abdominais.

Apresenta-se com dimorfismo sexual; nos $8^{8}$ e $9^{8}$ segmentos ab

dominais, na face ventral da pupa, encontram-se as estruturas genitais do macho e da fémea. A fémea apresenta um sulco em "V" invertido, no vértice uma pequena depressão elíptica, localizado no $8^{8}$ segmento. 0 macho possui duas pequenas saliéncias esféricas separadas por um sulco localizado no $9^{8}$ segmento.

No solo, as pupas são encontradas no interior dos casulos, estando estes localizados a $1,0 \mathrm{~cm}$ da superfície e com a abertura do casu lo voltada para cima.

A duraçèo do estágio pupal é de 5,60 $\pm 0,90$ (4 a 9 ) dias á temperatura de $27 \pm 5^{\circ} \mathrm{C}$ e U.R. $70 \pm 10 \%$. DUPRER (1965) observou 8.7 ( 10) dias à temperatura de $25 \pm 6^{\circ} \mathrm{C}$ e LEUCA (1960) encontrou o valor do $10 \pm 0,8$ dias para a mesma fase. 
o peso médio das pupas é de $22,98 \pm 4,45 \mathrm{mg}$; a proporção sexual dessa fase é de 1 macho para l, I fémea e a viabilidade de 92\%.

\subsubsection{Adulto}

Os adultos de E. Lignoscllus são pequenas mariposas, medin do entre 15 a $23 \mathrm{~mm}$ de envergadura. A coloração é extremamente variável, sendo que os machos fossuem a asa anterior de cor ocre-amarelada a cor de ferrugem e, a fêmea possui uma coloração mais escura, normalmente cinza escuro.

O dimorfismo sexual notado nessa fase é caracterizada pela presença de palpos labiais mais desenvolvidos nos machos que nas fëmeas, situado na cabeça e voltados para a região posterior - corpo. Essa carac terística é melnor visualizada lateralmente quando o inseto está em repouso.

A proporção sexual nessa fase foi de 1:1. STONE (j968) näo obteve alteração no número de espermatóforos transferidos quando alterou a proporção sexual de 1 macho para 1, 2, 3 e 4 fémeas.

A emergēncia do adulto ocorre dentro de 1 a 2 minutos e tempo para a distenção das asas foi de 5 a 10 minutos.

\subsubsection{Pré ovoposição}

A Tabelo 10 mostra que as mariposas de E. Riancsollw "y querem 2 dias para iniciarem a ovoposiçào, à $27 \pm 5^{\circ} \mathrm{C}$ e $70 \pm 10 \%$ U.下. IE ríodo de pré-ovoposição igual foi obtido por CHALANT (7975). A varjaçäo 
.40.
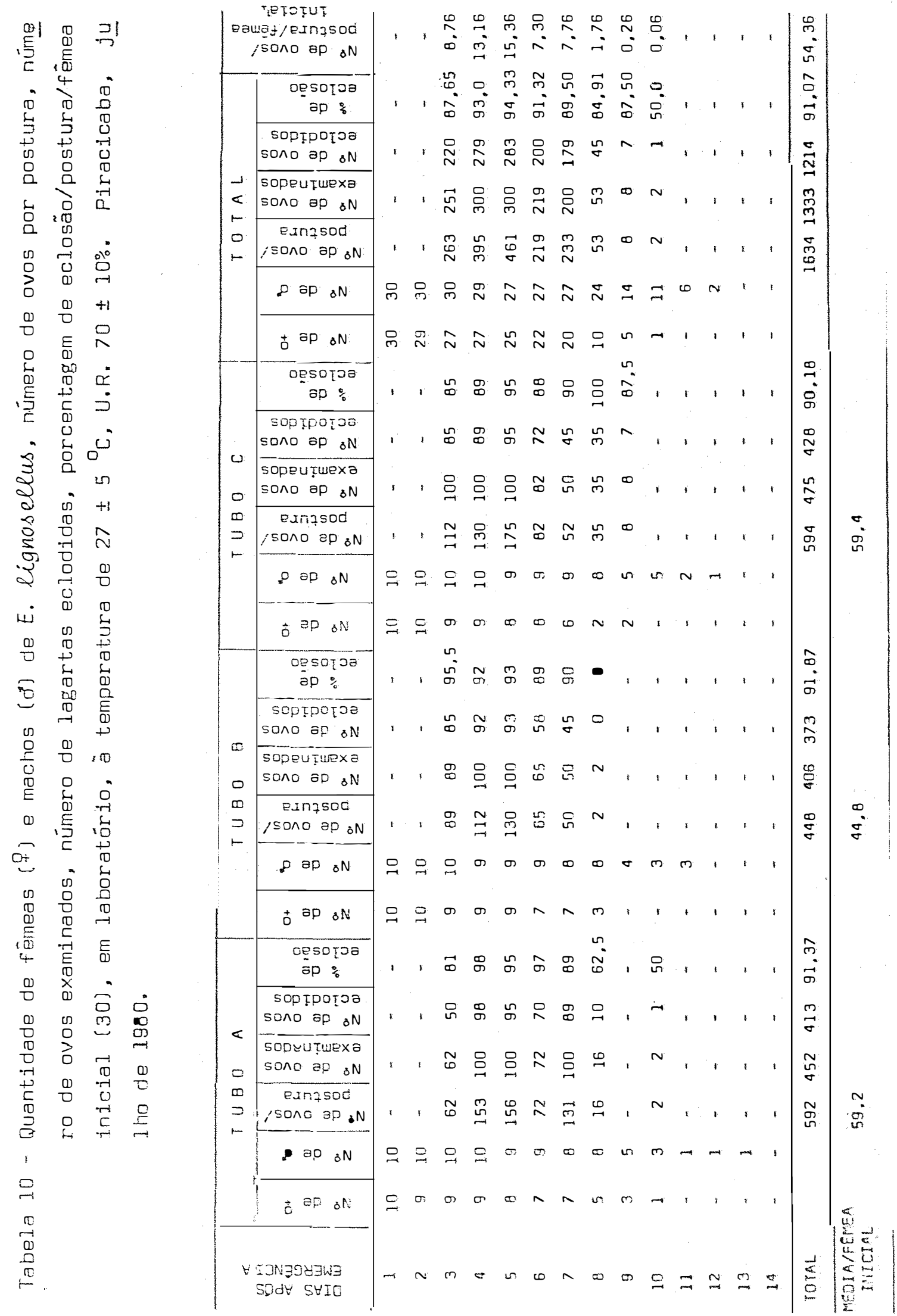
mínima e.máxima encontrada por DUPREE (1965), para o período de pré-ovopo sição foi de 2 a 6 dias, respectivamente, sendo a média de 3,4 dias.

\subsubsection{Postura}

As posturas foram efetuadas preferencialmente na ausência de luz; os ovos foram postos isoladamente nas depressões de fol ha de papel ou justapostos formando grupos. A regiāo preferida, no papel receptor de ovos, foi a parte superior, próxima à tampa do recipiente coletor de postu ra. Nas plantas de trigo (T. aestivum) ocorreram posturas próximas à su perfície do solo. CHALEANT (1975) determinou que a cor de maior atrativi dade para ovoposição foi a azul, sendo a superfície porosa igualmente pre ferida.

Na Tabela 10 encontra-se o número de ovos por fémea por dia, mostrando a ocorréncia do pico de ovoposição com 54\% do total, duran te o quarto e quinto dias de vida. O número total de ovos por fémea foi de 54 ovos, à temperatura de $27 \pm 5^{\circ} \mathrm{C}$ e $70 \pm 10 \%$ de U.R. CHALFAnT (1975) encontrou um pico de postura no quinto dia de ovoposição e o nú mero de ovos por fémea foi de 46 ovos.

\section{7.5.3. Longevidade}

A Tabela 10 mostra a sobrevivência de féneas e machos subme tídos à temperatura de $27 \pm 5^{\circ} \mathrm{C}$ e $70 \pm 10^{\circ}$ \% U.R.

\footnotetext{
A longevidade da fémea é de E,53 $\pm 2,21(1,0$ a 10,0$)$ dias e a do macno é de $8,60 \pm 2,27(3,0$ a 13,0$\}$ dias.
} 
.42 .

Em média, as fémeas ovopositaram 7,0 ovos por dia durante 8 dias de ovoposição, enquanto que CHALFANT (1975), trabalhando com ma riposas cujas larvas haviam sido desenvolvidas em dieta artificial, obteve 5, 1 ovos por dia durante 9 dias.

A curva de ovoposição de uma fêmea está representada na Fi gura 2.

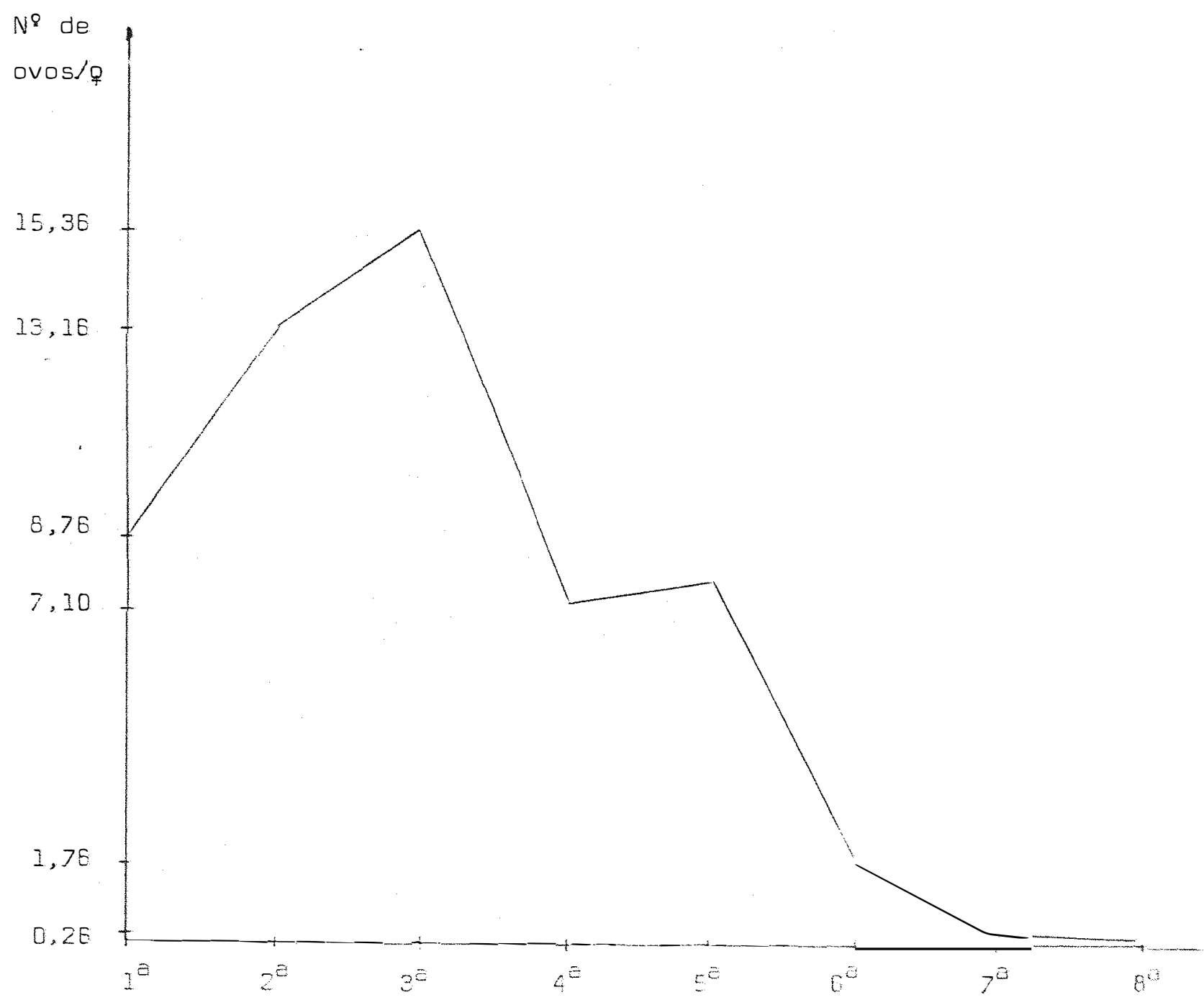

Figure 2. Curva representativa do $n^{8}$ de ovos/fémea $\times n^{8}$ da postura (me dia de 30 mariposas fëmeas de E. liznoscl(us), $27 \pm 5$ C,U.F. $70 \pm 10 \%$. Piracicaba, julho 1980. 
.43.

Os valores relatados por DUPREE (1965) fóram: para fímea, 14,6 (2-25) dias e para o macho $11,4 \cdot(2-23)$ dias, numa temperatura de $25 \pm 6^{\circ} \mathrm{C}$; para a longevidade das fémeas, CHALFANT (1975) encontrou um va lor de 5,0 ( 3 a 10) dias, enquanto que para os machos foi de 8,0 (4 - 12) dias

A longevidade média para ambos os sexos foi de 7,6 dias à temperatura de $27 \pm 5^{\circ} \mathrm{C}$ e $70 \pm 10 \%$ U.R.; IEIUCK (1966) determinou que foi de 22,3 dias a uma temperatura de $26^{\circ} \mathrm{C}$, enquanto que CHALEANT (1975) encon trou 6,5 dias.

\subsubsection{Ciclo Biológico}

Nas condições de laboratório, à temperatura de $27 \pm 5^{\circ} \mathrm{C}$ e U.R. $70 \pm 10 \%$, a E. lignosedlus apresentou o seguinte desenvoivimento médio: de ovo à eclosão da lagarta: 3,0 dias; estágio larval e pré-pupa: 10,74 dias: pupa: 5,60 dias e adulto: 7,56 dias, sendo requerido 26,90 dias para o completo desenvolvimento do ciclo (Tabela 11). 
Tabela 11 - Duraçào, em dias, de cada fase de vida de E. Lignosellus. Tem peratura: $27 \pm 5^{\circ} \mathrm{C}$ e U.R. $70 \pm 10 \%$. Piracicaba, SP. 1980.

\begin{tabular}{lcc}
\hline FASES & DURAÇAO EM DIAS & $\begin{array}{c}\% \text { REPRESENTADA } \\
\text { PELAS FASES }\end{array}$ \\
\hline Ovo & $3,00 \pm 0,00$ & 11,15 \\
18 instar & $1,30 \pm 0,34$ & 4,83 \\
28 instar & $1,59 \pm 0,61$ & 5,91 \\
$3^{8}$ instar & $2,10 \pm 0,74$ & 7,80 \\
$4^{8}$ instar & $2,39 \pm 1,23$ & 8,88 \\
$5^{8}$ instar & $0,80 \pm 0,96$ & 2,97 \\
68 e pré-pupa & $2,57 \pm 1,56$ & 9,51 \\
Pupe & $5,60 \pm 0,90$ & 20,81 \\
adulto & $7,56 \pm 1,46$ & 28,14 \\
\hline
\end{tabular}

4.2. Efeito da Frequéncia de Irrigação sobre Lagartas de E. lignosellus

A Tabela 12 mostra o número de plantas danificadas por lagartas de E. lignosclfus quando, lagartas e plantas, são submetidas aos di ferentes intervalos de irrigaçäo por aspersão.

o obetivo de adijao de camade superficial de areie rossa nas parcejas foi o de eliminar o efeito de variaça da textura do solo na camade superficiel. SAUEF (zezo) referiu-se a major incioencie dessa praga em soios leves que em solos areilosos, cultivados com arroz. ChaGAsh 1978 ? 
também observou alta incidéncia degta pragá em soja cultivada em solo are noso. CHALFANT (1975) determinou que para maior sobrevivéncia da lagarta de E. lignosellus em dieta artificial é necessária a adição de vermiculita na superfície da mesma.

Nas condições do experimento, a redução no "stand" com irrigação por aspersão a intervalos de 6,0 dias foi de 3,0\%, sendo nula quando a irrigação ocorreu em intervalos de 3,0 dias. ALL e GALLAHER (1977) observaram uma redução de 7,7\% no "stand" em culturas de milho irrigado sob cultivo convencional instaladas em diferentes tipos de solos, e $23,5 \%$ de redução do "stand" naquele não irrigado; a umidade do solo à profundida de de $15 \mathrm{~cm}$ foi de 5,0 \pm 2 bars na cultura irrigada e $11,0 \pm 6,1$ bars na cultura não irrìgada.

Considerando-se que a quantidaje de água fornecida por aspersão foi a mesma em todos os tratamentos no período do ensaio,parece ser a frequência de irrigação fator determinante na sobrevivència das lagartas de E. lignosellus, pois o número de pupas coletadas nas parcelas irrigadas de 3 e 6 dias foi nulo. BERTELS (1970) concluiu, em seus estudos da influência da umidade sobre a dinámica de populações de lepidópteros pragas de milho, que para a E. lignosellus os períodos de chuvas (30 dias) que antecedem o plantio do milho na zona litorànea do Río Grande do Sul. eliminam quase que por completo o perigo das futuras invesàes da geração primaveris. 
46.

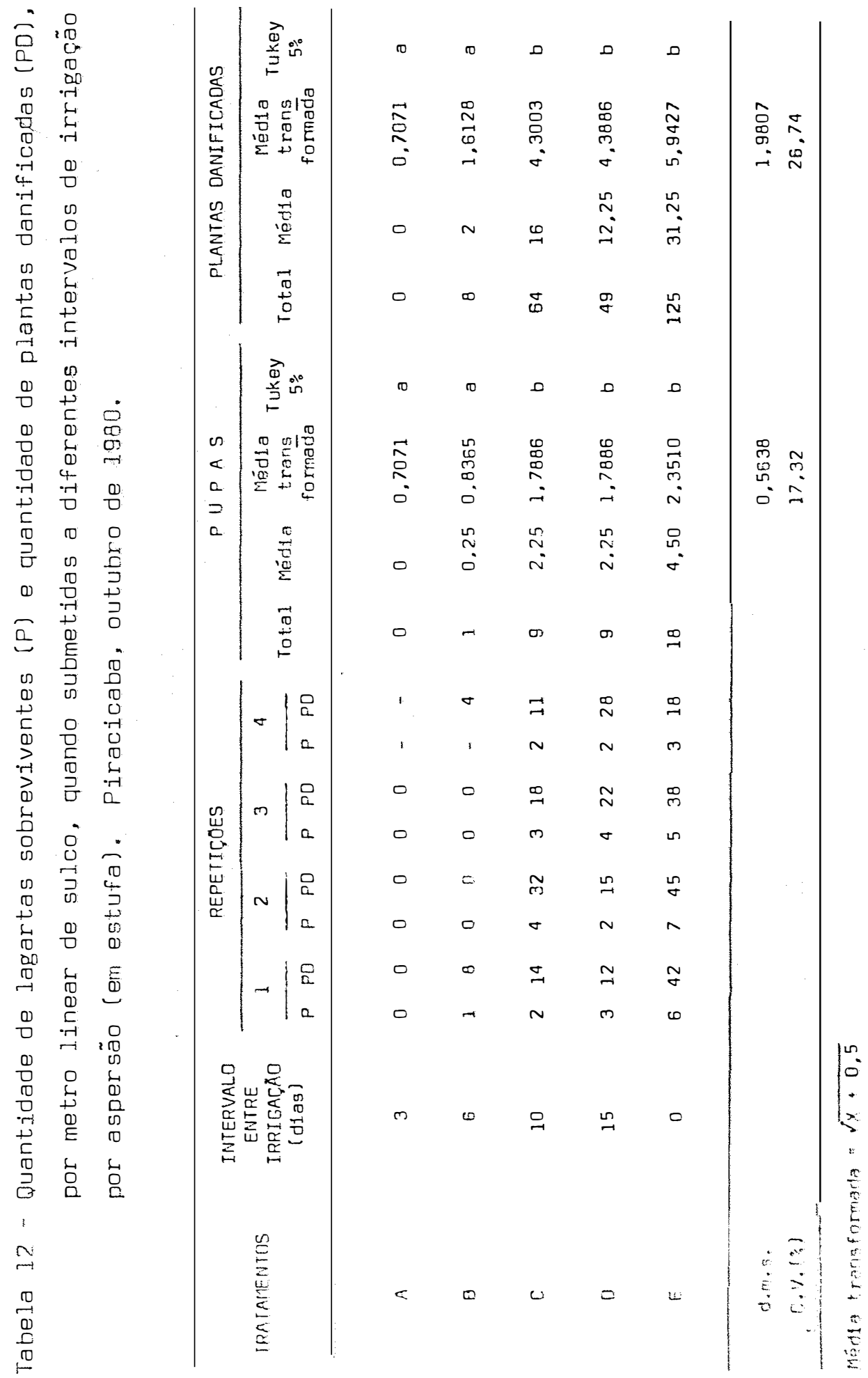


.47.

\subsection{Avaliação de Dano*}

\subsubsection{Sintomas do Dano}

Nas gramíneas os sintomas, de dano de lagartas de

E. lignosellus são: murchamento da folha central 10 dias após a infestaçào com larvas recém-eclodidas e posterior secamento da mesma, dando origem ao sintoma "coração morto". As lagartas atacam as plantas na regiäo abaixo do colo, $2,0 \pm 1,0 \mathrm{~cm}$ de profundidade, tecendo um tubo com fio de seda, areia e dejeções.

Nas leguminosas, soja e feijão, as lagartas de E. ligno sellus broqueiam a regiào abaixo do colo, as plantas murcham e posterior mente ocorre o seu tombamento.

4.3.2. Nümero provável de plantas de milho, sorgo sacarino, trigo, arroz, soja e feijão, danificadas por lagarta de E. lignosellus

Na Tabela 13 estão relacionados os nümeros prováveis de plan tas, das culturas citadas, danificadas por lagarta de E. lignosellus. Para o milho e sorgo sacarino os valores foram 2,57 e 2,78, respectivamente. ALL e GALLAHER (1979) consideraram planta de milho infestada aquela com "coração morto" ou morta, e obtiveram, para produção de gràos, a equação:

$y($ produçào perdida $\%)=0,98 \times(\%$ de infestaça $)+0,53$

$(r=0,94)$. 
.48.

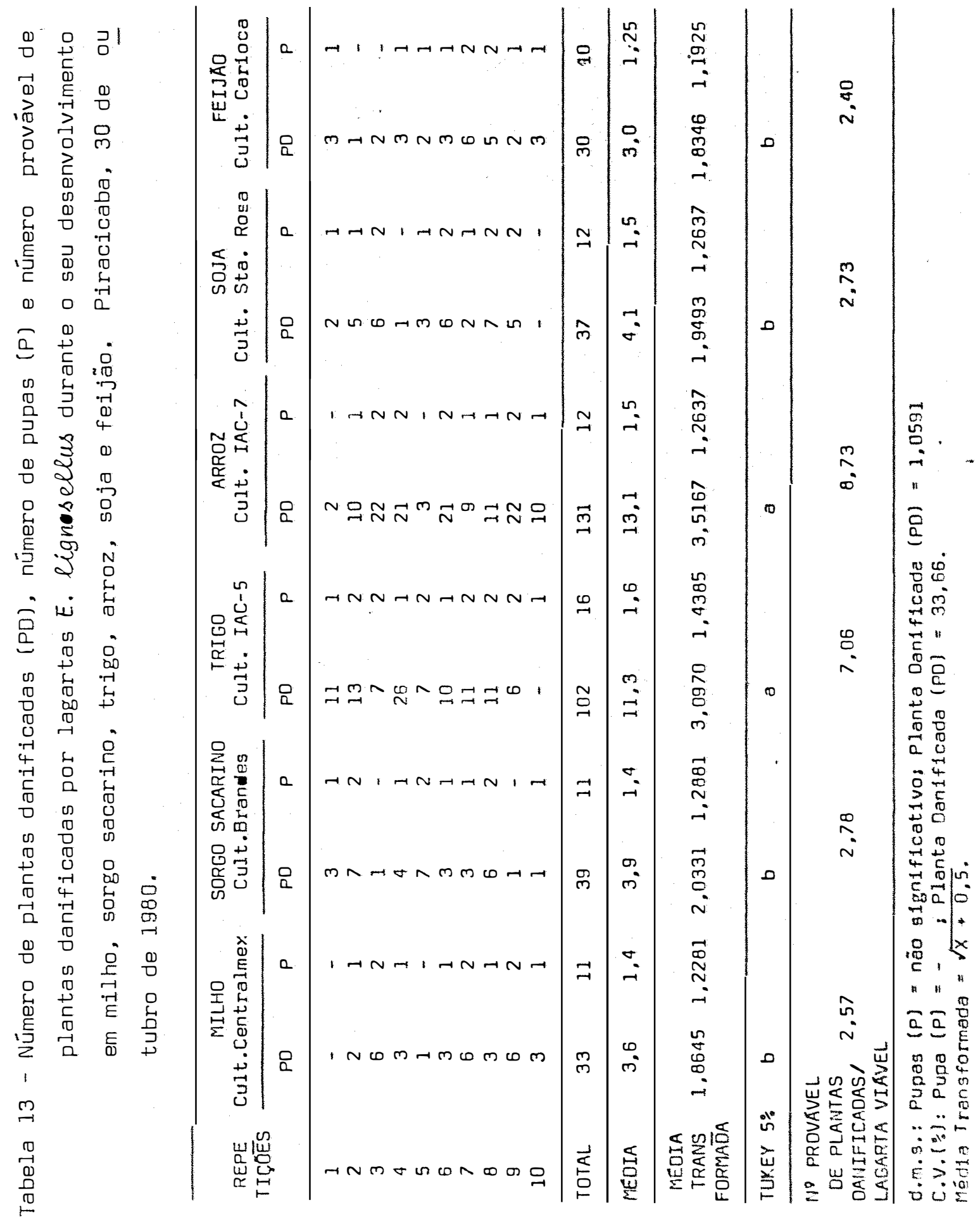


Para a cultura de arroz e trigo o número provável de plantas danificadas por lagarta foi de 8,75 e 7,05, respectivamente. SAUER (1939) encontrou, para o arroz plantado em cova, 4,0 plantas danificadas por lagartas elasmo. MARTINS et alii (1980) estabeleceram que uma lagarta de E. Lignosellus por litro de solo amostrado reduz em $1 \%$ o "stand" inicial de l,0 metro linear da cultura de arroz.

o número provável de plantas de feijoeiro e da soja danificadas pela lagarta foi de 2,40 e 2,73, respectivamente. Pela Tabela 13, 0 número de pupas entre os tratamentos não diferiram significativamente entre si, mostrando que em qualquer destes hospedeiros a sobrevivência larval foi a mesma, isto é, de 1,4; 1,4; 1,6; 1,5; 1,5 e 1,25 pupas/ parcela, respectivamente, para milho, sorgo sacarino, trigo, arroz, soja e feijäo, causando danos diferentes em função da espécie hospedeira.

\subsection{Controle}

\subsubsection{Fase seletiva I}

A Tabela 14 mostra os resultados obtidos no experimento I da fase seletiva, cujos inseticidas foram aplicados em pulverização no sulco. Os inseticidas que proporcionaram melnor germinaçào foram acefate PS. 1500; fonofos EC, 1000; e carbofuran F, 1000; em gramas do ingrediente ativo/ha, proporcionando uma germinação de $88,52 \%$, $85,92 \%$ e $87,04 \%$, respectivamente.

Os inseticidas dimetoato EC, 2500; clorpirifos etil EC. 3800 ; sulfona de aldicarb PM, 1500; metamidofos EC, 1500 e mefosfolan EC, 1000; 
em gramas do ingrediente ativo/ha, proporcionàram germinações intermediárias de $76,67 \% ; 73,70 ; 71,11 ; 76,11$ e $71,11 \%$, respectivamente, muito embora não tenham diferidos do primeiro grupo significativamente.

Em tratamento de sementes, foi observado por DOMICIANo(1979) que carbofuran F, 700 gramas de ingrediente ativo por $100 \mathrm{~kg}$ de semente de arroz, propiciou a germinação de 341,5 plantas de 700 sementes viáveis co locadas no solo na semeadura; o inseticida acefate PS, 3210 gramas de. In grediente ativo por $100 \mathrm{~kg}$ de semente de arroz, por sua vez, propiciou a emergència de 330 plantas por 700 sementes viáveis de arroz.

A porcentagem de reduçào no "stand" inicial consta da Tabe la 14, sendo que a. pulverização do sulco com dimetoato EC, propoxur PM. clorpirifos etil EC, acefatePS, fonofos EC, carbofuran F e mefosfolan pro piciaram uma reduçāo percentual de 6,$76 ; 3,61 ; 5,03 ; 15,90 ; 0,86 ; 4,26$ e 7,29, respectivamente, no "stand" inicial, não diferindo significetivamen te entre si, mas diferindo dos demais lsulfona de aldicarb PM. metamidofos EC e testemunha).

A eficiéncia da aplicaçào de inseticidas na superfície do solo, em faixa de $20 \mathrm{~cm}$, foi verificada por DOMICIANo (1979), para os produtos acefate PS, clorpirifos EC e carbofuran PM, nas dosagens de 2.13: 0,720 e $0,750 \mathrm{~kg}$ do ingrediente ativo/ha, respectivamente, sem eficiencia no controle da lagarta Elasmo, em cultura de arroz. ALL (1978) obteve boa eficiéncia do carbofuran $G$ e clorpirifos etil $G$ aplicados acima do sulco de semeadura e incorporado no solo, ambos na dose de 2350 gramas do ingre diente ativo/ha, em milho. 


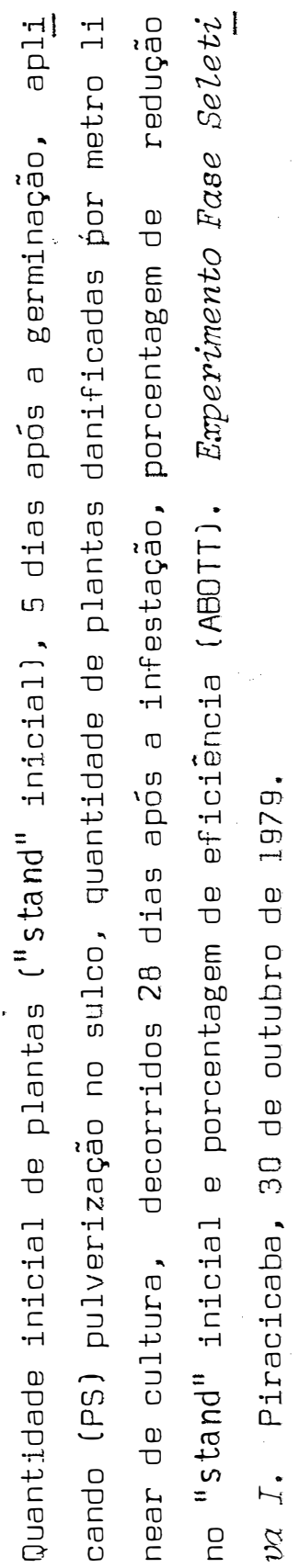

+
$\square$
0
0
0
0
0

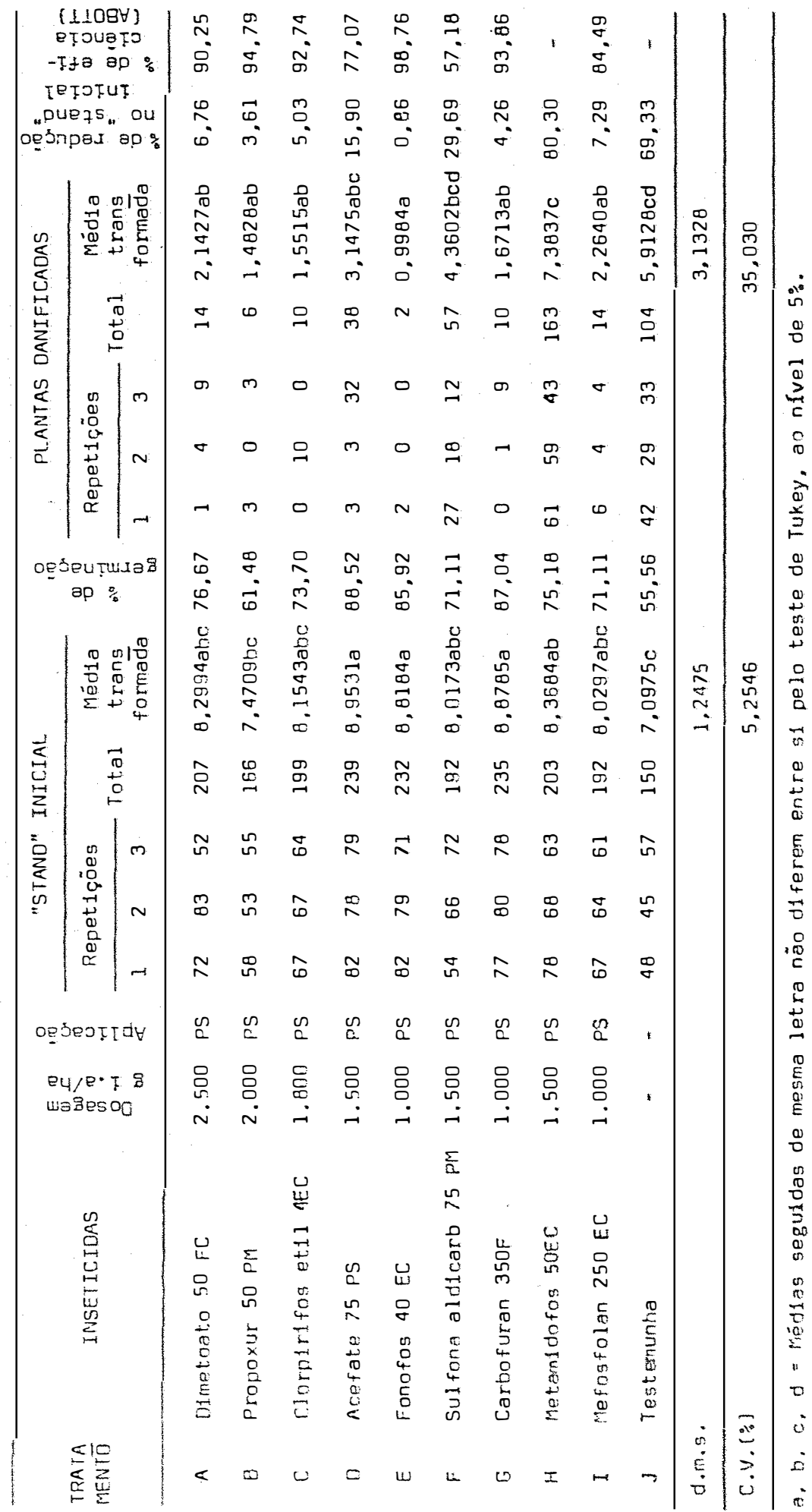


A Tabela 14 mostra a eficiéncia do clorpirifos etil EC, fo nofós EC, carbofuran F e propoxur PM, nas doses de 1800, 1000, 1000 e 2000 gramas do ingrediente ativo/ha, respectivamente, evitando os danos da la garta elasmo, muito embora dimetoato EC, propoxur PM, acefate PS e mefosfolan EC, nas proporções de 2500, 2000, 1500 e 1000 gramas do ingrediente ativo/ha, não tenham diferido significativamente do primeiro grupo. Os inseticidas menos eficientes na manutenção do "stand" inicial foram o metamidofos EC e sulfona de aldicarb, ambos a 1500 gramas do ingrediente ativo/ha, pulverizados no sulco.

\subsubsection{Fase seletiva II}

A Tabela 15 ilustra os resultados obtidos no experimento 2 da fase seletiva, cujos inseticidas foram aplicados em tratamentos de se mente.

Os inseticidas que mais afetaram a germinação das sementes foram: propoxur PM, 2000 e clorpirifos etil EC, 1800, em gramas de ingre diente ativo por $120 \mathrm{~kg}$ de semente, proporcionando uma germinação de 73,3 e $68,4 \%$, respectivamente.

Os produtos metamidofos EC, 1500, acefate PS, 1500, sulfone de aldicarb PM, 1500, carbofuran F, 1000, em gramas de ingrediente ativo por $120 \mathrm{~kg}$ de semente, proporcionaram $81,48 \%, 87,78 \%, 8556 \%$ e $80,0 \%$, respectivamente, contra $88,15 \%$ de germinação da testemunha, e não diferiram significativamente entre si. Germinação semelhante foi obtida por MARTMS et alii (1980) para o inseticida carbofuran PM, na proporção de 750 grar 
.53.

mas do ingrediente ativo por $100 \mathrm{~kg}$ de semente de arroz, proporcionando $81,0 \%$ de germinação.

GOMES (1980) observou que o acefate PS, na proporção de 1500 gramas de i.a/100 kg de semente de trigo, quando utilizado na época normal, foi fitotáxico, e quando a semeadura foi realizada na época de seca foi altamente fitotóxico, mesmo nas doses mais baixas $1750 \mathrm{~g} \mathrm{i.a/100} \mathrm{kg}$ de semente]. Em relação à sulfona de aldicarb, 1500 gramas de i.a/lo0 kg de semente, apresentou uma fitotoxidade média, retardando a germinação em 13 dias e proporcionando um "stand" inicial de $3.083,33$ plantas/15 $\mathrm{m}^{2}$ (46\% de germinação) contra $3.802,83$ plantas $/ 15 \mathrm{~m}^{2}$ (56\% de germinação) da teste munha.

Os resultados obtidos por CAMPOS (1972), que empregou meta midofos EC nas doses de 150, 210 e 380 gramas do ingrediente ativo por $100 \mathrm{~kg}$ de semente de milho, e obteve $56,0 \%, 71,5 \%$ e 45,3\% de germinaçào, foram contrários aos resultados aqui obtidos, muito embora as plantas testadas fossem diferentes.

A Tabela 15 mostra que os produtos mais vantajosos na manu tenção do "stand" inicial foram propoxur PM, 1500, clorpirifos etil EC. 1800, e carbofuran F, 1000, em gramas do ingrediente ativo por $120 \mathrm{~kg}$ de semente, com porcentagem de redução no "stand" de 19,70\%, 8,70\% e 5,09\%, respectivamente, näo diferindo significativamente entre si. Os demais produtos foram pouco efetivos, permitindo uma elevada porcentagem de reducáa no "stand" iniciai.

O inseticida mais eficiente foi o carbofuran F. resultado 


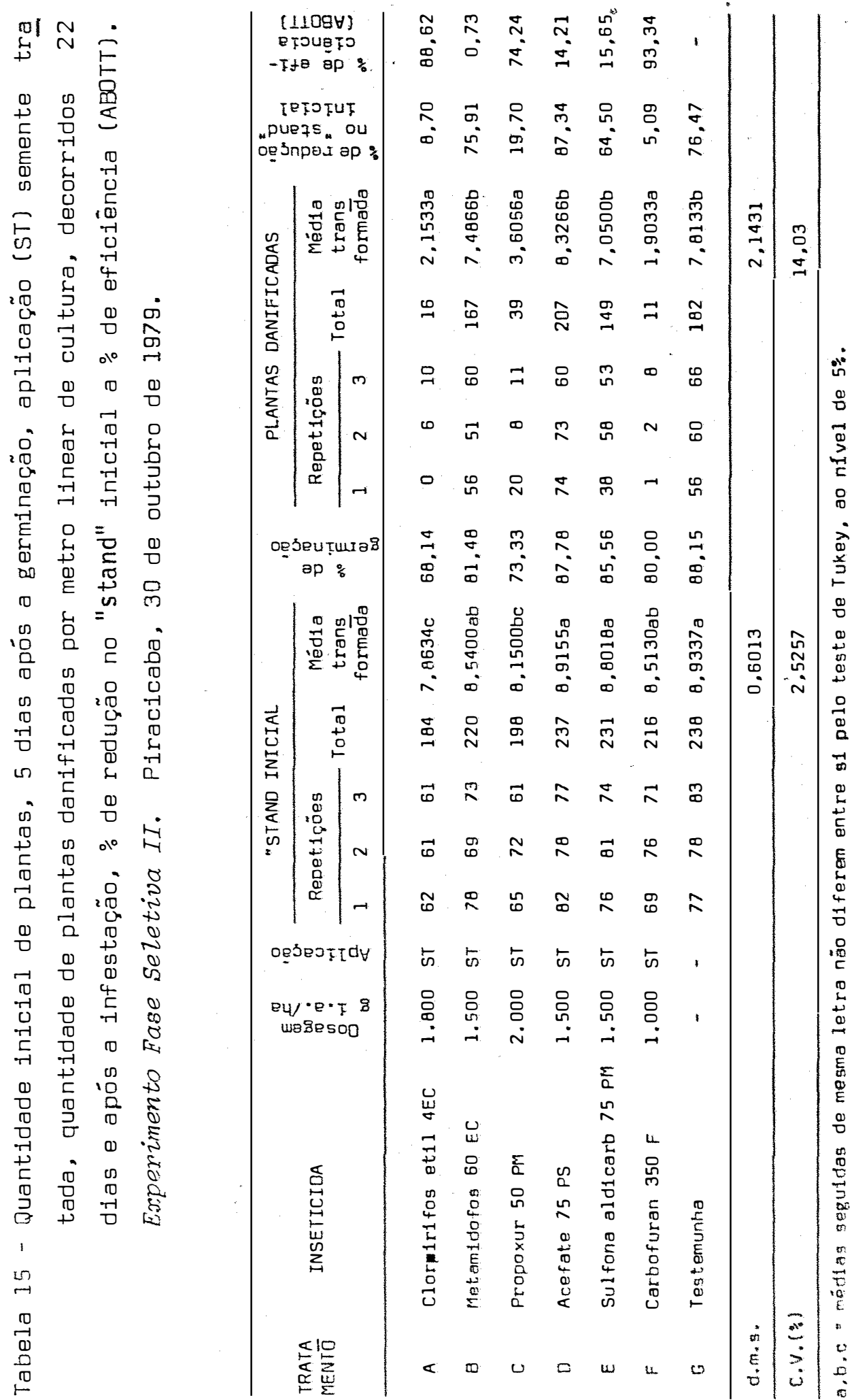


esse semelhante ao obtido por GOMES (1980). Este mesmo autor observou que, nas doses de 350, 700 e 1050 gramas de i.a por $100 \mathrm{~kg}$ de sementes de trigo, houve um eficiente controle, e a medida que se aumentou a dosagem de car bofuran 3F diminuiu o número de plantas atacadas pela lagarta de E. ligno sellus.

Acefate PS foi pouco eficiente no experimento 2, igualando-se à testemunha. GOMES (1980), em trés experimentos, verificou que de 101, 48 e 266 plantas iniciais/parcela o acefate permitiu uma redução no "stand" para 75, 42 e 41 plantas, respectivamente. O inseticida sulfona de aldicarb PM foi pouco eficiente para o controle da lagarta Elasmo,e estes resultados são concordantes com os de GOMES (1980).

D inseticida clorpirifós etil EC e propoxur PM não tèm sido referidos nesse tipo de aplicação, muito embora tenham se mostrado eficien tes no controle desta praga. Eles foram altamente tóxicos à germinaçào, quando em tratamento de sementes.

\subsubsection{Experimento confinativo}

A Tabela 16 mostra os resultados referentes ao ensaio confirmativo e eficiéncia dos inseticidas na prevenção dos danos da lagarte Eiasmo.

Exceptuando-se o acefate PS, 1500 gramas i.a/120 kE de $50-$ mente, todos os demais produtos não diferiram significativamente da testemunha com relação ao "stand" inicial. GOMES (1980) referiu-se à toxicida- 
de desse produto na mésma forma de tratamento e proporção.

Dentre todos os tratamentos, o produto que destacou-se pelo pequeno efeito no controle foi o acefate PS em tratamentos de semente, não obtendo eficiència.

Destacaram-se os inseticidas clorpirifós etil EC, 1800 e 2100 gramas de ingrediente ativo/ha, pulverizado no sulco, e carbofuran F, 1000 gramas de i.a/120 kg de semente, com eficiència de 81,88, 83,99 e $76,92 \%$, respectivamente.

O inseticida etoprop EC, 1000 e 1260 gramas de i.a/ha resul tou num controle de 54,30 e $49,91 \%$ de eficiēncia, sendo este produto referido por ALL et alii (1979), com um controle de 17\%, quando comparado com a testemunha.

Comparando-se os dois tipos de aplicaçào para o carborufan F, em tratamento de semente e pulverização no sulco, nota-se uma efetivida de superior do primeiro tipo de aplicação, com 14,7\% de reduçào no "stand" inicial contra 28,80 e $31,70 \%$ de redução do segundo tipo de aplicação, muí to embora em maior dosagem.

Dos Ensaios com Inseticidas em Conjunto

Considerando-se as informaçóes obtidas do ponto de vista de eficiència e reduçào na germinação das sementes de trigo, dos insetícídas carbofuran $350 \mathrm{~F}$, fonofós 4 EC, clorpirifós etil a EC e $15 \mathrm{G}$, sugere-se e inclusão dos mesmos em outras condições experimentais. Para tanto, as do- 


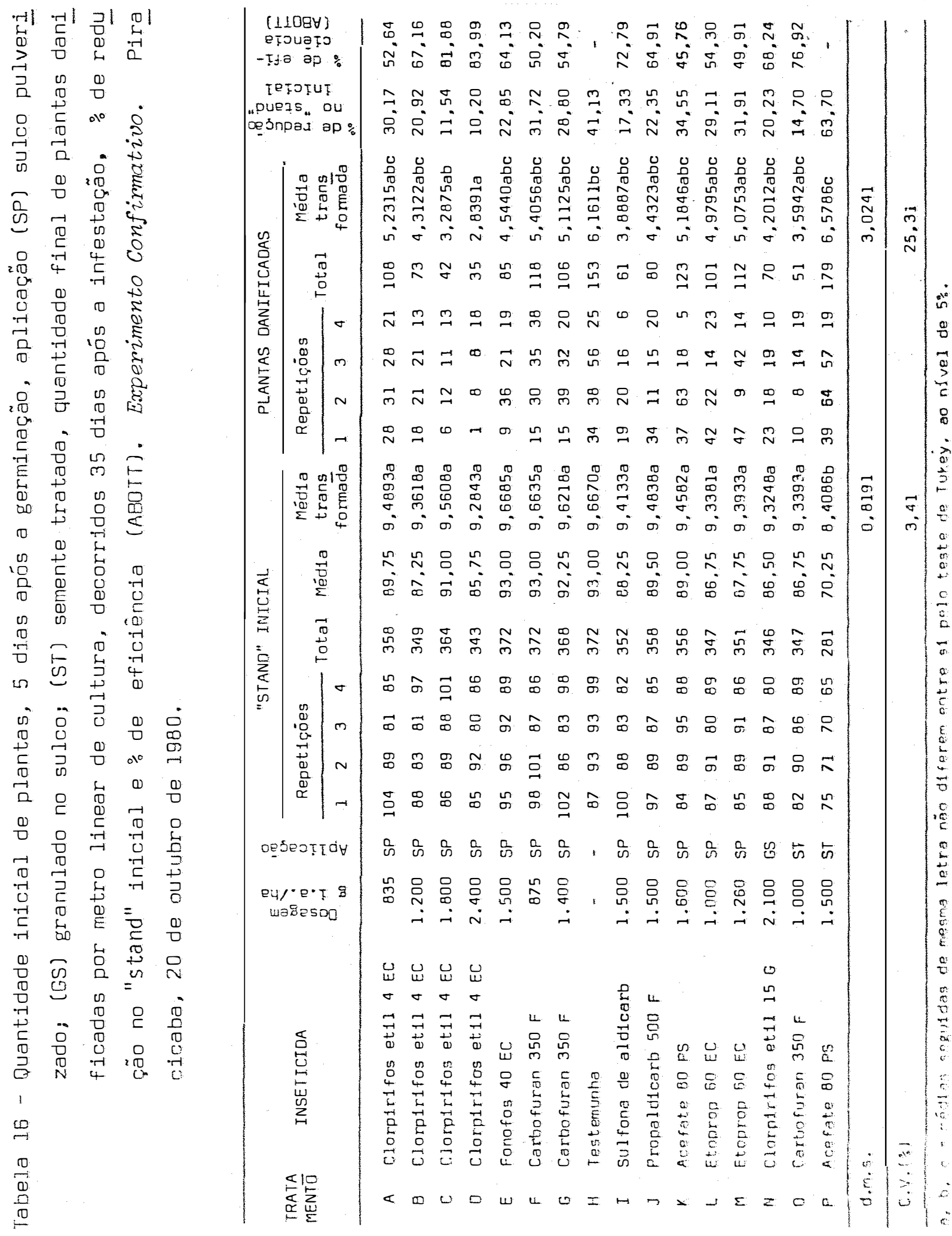


.58 . sagens de corpirifos etil deverão variar entre 1000 e 1800. gramas do ingre diente ativo/ha em tratamento de sulco, não. preconizando o tratamento de semente. As dosagens de fonofós 4 EC e carbofuran $350 \mathrm{~F}$ deverão ser supe riores a 1000 gramas de ingrediente ativo/ha, quando pulverizados no sul co, e carbofuran $350 \mathrm{~F}$ em doses inferiores a 1000 gramas de i.a/120 kg de sementes. 


\section{CONCLUSÕES}

Os resultados obtidos da presente pesquisa com Elasmopalpus lignosellus (ZeZZer 1848), permitiram estabelecer as seguintes conclusões:

- 0 ciclo biológico desse inseto, em condições de laboratório, foi de $26,9 \pm 7,80$ dias à temperatura de $27 \pm 5^{\circ} \mathrm{C}$ e $70 \pm 10 \%$ U.R.

- 0 número de ovos por fémea foi, em média, de 54,36 ovos distrí buídos durante 8 dias do período de postura; o período de pré-ovoposiçáo foi de 2 dias;

- A fase larval apresentou 6 instares que podem ser determinados aㅡ través da medição de frações de uma população cujo indivíduos possuam a mesma idade inicial e possam ser submetidos às mesmas condições de ambien te éalimentação. A razão de crescimento da cápsula cefálica foi de 1,35;

- O número médio de plantas danificadas de: trigo, milho, sorgo secarino, arroz, soja e feijão por lagaria elasmo, foram: 8.73; 2,57; 2.76; 7,$06 ; 2,73$ e 2,40 respectivamente. 
.60 .

- Irrigações por aspersão com intervalos de $3^{*}$ a $\dot{6}$ diás reduziram o número de plantas danificadas para $0 \%$ e $3 \%$, e a viabilidade larval para 0,0 e $2,5 \%$, respectivamente.

- Ds inseticidas clorpirifos etil EC e G, fonofos EC, carbofuran F, sulfona de aldicarb, tiodicarb F, acefate PS e etoprop EC, pulverizados no sulco de semeadura, não afetaram a germinação das sementes de trigo, in clusive nas doses mais altas;

- Em tratamento de semente, os inseticidas que reduziram a germina ção foram; propoxur PM, clorpirifos etil EC, acefate 80 PS, nas dosagens de 2000, 1800 e 1500 gramas do i.a/120 kg de semente, respectivamente;

- Em tratamento de sementes os produtos que não alteraram-a germi nação foram: metamidofos EC, carbofuran $F$ e sulfona de aldicarb PM, nas do sagens de 1500, 1000 e 1500 gramas de i.a/120 kg de semente, respectivamen te;

- Os produtos mais eficientes na redução dos danos causados pela lagarta de elasmo, na cultura do trigo foram: carbofuran $F$, em tratamento de sementes; fonofos EC, pulverizado no sulco de semeadura; clorpirifos etil EC, pulverizado no sulco de semeadura, nas dosagens de 1800 e 2400 grames de i.a/ha. 


\section{LITERATURA CITADA}

ALL, J.N., 1978. Seet corn, lesser cornstalk borer control. In: Entomolo gical Society of America - Insecticide and Acaricide Test. College Park. $V(3), P, 74$.

ALL, J.N. e R.N. GALLAHER, 1977. Detrimental impact of notillage corn cropping systems involving insecticides, hybrids and irrigation on lesser cornstalk borer infestations. J. Econ. Ento. 70(1): 361-365.

ALL, J.N.; R.N. GALIAHER E M.D. JELLUM, 1979. Influence of planting date, preplanting weed control, irrigation, and conservation tillage practices on efficacy of planting time insecticide applications for control of lesser cornstalk borer in field corn. J. Econ. Entomol. 72(2): 265-268.

BERTELS, A., 1970. Estudos da influēncia da umidade sobre a dinämica de populações de lepidopteros, pragas do milho. Pesq. Agrop. Fras. 5: 67-79.

BERTELS, A.M. 1977. Problemas das lagartas subterràneas em culture de soja. Agros V(XII): 35-38. 
.62 .

BERBERET, R.C.; R.D. MORRISON e R.G. WALL, 1979. 'Yield reduction caused by the lesser cornstalk borer in no irrigated spanish peanuts. J. Econ. EntomoZ. 72[4]: 526-528.

CAMPOS, P.J., 1972. Insecticidasimprégnados a la semilla del maiz para el control de Elasmopalpus lignosellus ZeZZer (Lepidoptera-pyralidae). Revista Per. Entom. 15(2): 348-351.

CHAGAS, E.F. das, 1978. Ocorréncia da lagarta Elasmo atacando soja em São Luiz. In: EMAPA - Empresa Maranhense de Pesquisa Agropecuária. Comunicado Técnico I: $4 \mathrm{p}$.

CHALEANT, R.B., 7975. A simplified technique for rearing the lesser cornstalk borer (Lepidoptera-Phycutudae). J. Georgia Entomol. Soc. 10(1): 33-37.

CORSEUIL, E. e A. TERHORST, 1971. Ensaio de controle a Elasmopalpus ligno sellus (ZeZzer, 1848) (Lepidoptera, Phycitidae). In: Arq. Mus. Nac., Rio de Janeiro, LIV: $4 \geq-43$.

CUNNINGHAN, W.H.; D.R. KING e B.C. LANGLEY, 1959. Inseticidar control of the cornstalk borer on peanut. J. Econ. Entomol. 5(2): 329-330.

DICKSON, D.W.; R.E. WAITES e J.A. CORNELL, 1978. Lesser cornstaik borer and Nematode control on field corn in Florida. IN: Entomological Society of America - Insecticide and Acaricid Tests. College Park. V.(3). p.119-121. 
DOMICIANO, N.L., 1979. Combate químico à lägarta Elasmo IElasmopalpus lignosellus) (Zezler, 1848) (Lepidoptera, Phycitidae) em cultura de ar roz, Ponta Grossa (PR), 1977-1978. In: Anais de "I Reunião de Técnicos em Rizicultura do Estädo de São Paulo. 291-303.

DUPREE, M., 1965. "Observations on the life history of the lesser cornstalk borer. J. Econ. Entomoz. 58(6): 1156-1157.

FEHN, M.L. e F.S. da MOTA, 1959. Influéncia da umidade do solo sobre o ataque de lagartas de Elasmopalpus lignosellus ao milho, en condiçōes de campo. Boletim do Instituto Agronōmico do Suz 22: 1-9.

GALLO, D.; O. NAKANO; S. SILVEIRA NETO; R.P.L. CARVALHO; G.C. BATISTH; E. BERTI FILHO; J.R.F. PARRA; R.A. ZUCCHI e S.ALVES, 1978. Manual de Entomologia Agrícola. 531p. Editora Ceres. Piracicaba, SP.

GOMES, S.A., 1980. Controle da lagarta Elasmopalpus lignosellus (Zezzer, 1848) através do tratamento de trigo com inseticidas. VI Reunião da Comissão Norte Brasileira de Pesquisa de Trigo. Curitiba, PR. p. 152-164.

HARDING, J.A., 1960. Control of the lesser cornstalk borer attacking peanuts. J. Econ. Entomol. 53[4]: 664-66].

HAYWARD, K.d., 1943. A mariposa perfuradora da cana-de-açúcar. Brasiz Açuareiro, novembro, p. 84-87.

HENDERSON, C.A.; K.C. EREEMAN E M.E. DAVIS, 1973. Chemical control of lesser cornstalk borer in Sweet Sorghum. J. Econ. Entomo2. 66 (5): 1233. 
.64.

LEUCK, D.B., 1967. Lesser Cornstalk. Borer Damage to Peanut Plant. J. Econ. Entomo2., 60(6): 1549-1551.

LEUCK, D.B., 1966. Biology of the lesser cornstalk borer in South Georgla. J. Econ. Entomo 2. 59(4): 797-801.

MARTINS, J.F. da S.; E. FERREIRA; A.S. PRABHU e F.J.P. ZIMMERMANN, 1980. Uso preventivo de produtos químicos para controle das principais pragas subterrāneas do arroz-de-sequeiro. Pesq.Agrop.Bras. 15(1): 53-62.

NAKANO, O. e S. SILVEIRA NETO, 1975. EntomoZogia Econômica. ESALQ, Pira cicaba, SP. $387 \mathrm{P}$.

PLANK, H.K., 1928. The lesser corn stalk-borer IElasmopalpus lignoscllus, ZeZZerl injuring sugar cane in Cuba. J. Econ. Entomoz. 21(2): 413-418.

PROGNOSTICO 80/81. In: Secretaria da Agricultura do Estado de São Paulo. Instituto de Economia Agrîcola. p. 111-113.

REYNOLDS, E.T.; L.D. ANDERSON E L.A. ANDRES, 1959. Cultural and chemical control of the lesser cornstalk borer in Southern California. J. Econ. Entomo2. $52(1):$ 63-66.

SAUER, H.F.G., 1939. Notas sobre "Elasmopalpus signosellus Zelier" lLep. Pyr.J, séria praga dos cereais no Estado de São Paulo. In: Arquivos do Instituto Biológico 10: 199-208.

SMITH JR., J.W. e R.L. HOLLOWAY, 1979. Lesser conrstalk borer larva] density and damage to peanuts. J. Econ. Entomoz. 72[4]: 535-537. 
STONE, K.J., 1968. Reproductive biology of the lesser cornstalk borer. I. Rearing technique. J. Econ. Entomol. $61[6]$ : 1712-1714.

STONE, K.J., 1968. Reproductive biology of the lesser cornstalk borer.

II. Cage conditions and sex ratios matin. J. Econ. Entomol. 61(6): 17151716.

YOKOYAMA, M. e O. NAKANO, 1977. Controle da lagarta Elasmo, Elasmopaîpus signosellus (Zeller, 1848) (Lepidoptera-Pyralidae) através de sementes tratadas com carbofuran. O Solo 2: 41-42. 